Article

\title{
Evaluation of the Different Compatibility Indices to Model and Predict Oil Colloidal Stability and Its Relation to Crude Oil Desalting
}

\author{
Ivelina K. Shishkova ${ }^{1}\left(\mathbb{D}\right.$, Dicho S. Stratiev ${ }^{1, *}{ }^{\mathbb{D}}$, Mariana P. Tavlieva ${ }^{1}$, Rosen K. Dinkov ${ }^{1}$, Dobromir Yordanov ${ }^{2}$, \\ Sotir Sotirov ${ }^{2}$, Evdokia Sotirova ${ }^{2}$, Vassia Atanassova ${ }^{3}{ }^{10}$, Simeon Ribagin ${ }^{3}$, Krassimir Atanassov ${ }^{2,3}$, \\ Danail D. Stratiev ${ }^{3}$, Liliana Todorova-Yankova ${ }^{2}$ and Svetoslav Nenov ${ }^{4}$ \\ 1 LUKOIL Neftohim Burgas, 8104 Burgas, Bulgaria; Shishkova.Ivelina.K@neftochim.bg (I.K.S.); \\ Tavlieva.Mariana.P@neftochim.bg (M.P.T.); Dinkov.Rosen.K@neftochim.bg (R.K.D.) \\ 2 Laboratory of Intelligent Systems, Department of Industrial Technologies and Management, \\ University Prof. Dr. Assen Zlatarov, 8010 Burgas, Bulgaria; dobromirj@abv.bg (D.Y.); ssotirov@btu.bg (S.S.); \\ esotirova@btu.bg (E.S.); k.t.atanassov@gmail.com (K.A.); litoian@abv.bg (L.T.-Y.) \\ 3 Institute of Biophysics and Biomedical Engineering, Bulgarian Academy of Sciences, \\ Academic Georgi Bonchev 105, 1113 Sofia, Bulgaria; vassia.atanassova@gmail.com (V.A.); \\ sim_ribagin@mail.bg (S.R.); danail.stratiev@gmail.com (D.D.S.) \\ 4 Department of Mathematics, University of Chemical Technology and Metallurgy, Kliment Ohridski 8, \\ 1756 Sofia, Bulgaria; s.nenov@gmail.com \\ * Correspondence: stratiev.dicho@neftochim.bg
}

Citation: Shishkova, I.K.; Stratiev, D.S.; Tavlieva, M.P.; Dinkov, R.K.; Yordanov, D.; Sotirov, S.; Sotirova, E.; Atanassova, V.; Ribagin, S.;

Atanassov, K.; et al. Evaluation of the Different Compatibility Indices to Model and Predict Oil Colloidal Stability and Its Relation to Crude Oil Desalting. Resources 2021, 10, 75. https://doi.org/10.3390/

resources 10080075

Academic Editor: Ben McLellan

Received: 18 June 2021

Accepted: 16 July 2021

Published: 22 July 2021

Publisher's Note: MDPI stays neutral with regard to jurisdictional claims in published maps and institutional affiliations.

Copyright: (c) 2021 by the authors. Licensee MDPI, Basel, Switzerland. This article is an open access article distributed under the terms and conditions of the Creative Commons Attribution (CC BY) license (https:/ / creativecommons.org/licenses/by/ $4.0 /)$.
Abstract: Thirty crude oils, belonging to light, medium, heavy, and extra heavy, light sulfur, and high sulfur have been characterized and compatibility indices defined. Nine crude oil compatibility indices have been employed to evaluate the compatibility of crude blends from the thirty individual crude oils. Intercriteria analysis revealed the relations between the different compatibility indices, and the different petroleum properties. Tetra-plot was employed to model crude blend compatibility. The ratio of solubility blending number to insolubility number was found to best describe the desalting efficiency, and therefore could be considered as the compatible index that best models the crude oil blend compatibility. Density of crude oil and the n-heptane dilution test seem to be sufficient to model, and predict the compatibility of crude blends.

Keywords: crude oil; crude oil characterization; compatibility; compatibility modelling; intercriteria analysis; desalting efficiency

\section{Introduction}

The cost of crude accounts for between 80 and 90-95\% of the total running costs of refineries, and therefore is the single most important determinant for the profitability of an oil company [1-3]. Therefore, refiners seek ways to process cheaper petroleum crudes, while minimizing the risk of equipment failure and unplanned shut down [4]. The cheaper crude oils, also called "opportunity crudes" are usually heavier with a higher concentration of compounds containing heteroatoms such as sulfur, nitrogen, oxygen, and metals [4-7]. Typically, in a refinery a blend of crude oils is processed rather than a single crude oil to ensure that an optimum product mix can be obtained at minimum costs. Refining margins can be improved by co-processing heavy crude oils with light crude oils [8]. Unfortunately, the co-processing heavy with light crude oils is frequently connected with incompatibility issues [9-12]. This can explain why the crude oil incompatibility has been a subject of numerous investigations [13-22]. Different methods have been developed, tested, and proposed to assess crude oil incompatibility [8,10-12,23-48]. Some of these methods employ sophisticated equipment and procedures, which, unfortunately, are unavailable in refineries for regular monitoring of the optimal crude oil blending and are suitable for 
blends of two crude oils. For each additional crude oil added to a blend, the number of lab tests required to ascertain the range of incompatibility goes up exponentially making the determination of crude oil compatibility intractable in laboratory testing [42]. On another hand, some authors $[8,34,39,44]$ reported that different procedures may qualify certain crude oil blend as compatible or incompatible depending on the used crude oil properties and laboratory conditions. In this study, we characterized thirty crude oils from all over the world, twenty two of which were processed in the Lukoil Neftohim Burgas (LNB) refinery. Nine crude oil compatibility indices, easy to apply in refineries, were employed to assess the colloidal stability and the affinity to form precipitation during blending. Then these indices were contrasted with the performance of LNB crude desalting units during processing different crude blends to discriminate those indices which are best linked to the desalting efficiency. Desalting efficiency is related to crude compatibility, lowering it when crude blend is incompatible [14]. Poor desalting was reported in our previous studies to lead to upset and emergency shutdown of one of the LNB middle distillate hydrotreaters $[17,49]$ due to excessive fouling with ammonium chloride settled down in the hydrotreater water coolers.

Crude compatibility is still an ill-defined area in terms of its measurement and evaluation [38]. Most studies relate crude incompatibility to a higher fouling rate [2,15,16,18,21,22,27]. Little is published about the relationship of crude incompatibility to desalting efficiency. Moreover, there is a lack of reports indicating the dependence of crude desalting efficiency on the compatibility indices employed to characterize crude compatibility. That was the reason why we performed this study with the aim to discuss the relations between crude oil compatibility indices and desalting efficiency. Additionally, we investigated the relationships between petroleum characterization parameters and the compatibility indices.

\section{Materials and Methods}

\subsection{Crude Oil Characterization}

Thirty crude oils originating from Russia, Azerbaijan, Kazakhstan, Turkmenistan, Libya, Egypt, USA, Venezuela, Equatorial Guinea, Saudi Arabia, Kuwait, Greece, Albania, Italy, Tunisia, and others were investigated in this work. These thirty crude oils include light low sulfur, light sulfur, intermediate low sulfur, intermediate sulfur, intermediate high sulfur, heavy high sulfur, and extra heavy high sulfur crudes. Twenty-two of them were processed in the LNB refinery, and eight of them were considered for possible processing in the refinery.

The crude oils were fractionated in a true boiling point (TBP) Euro Dist System from ROFA Deutschland $\mathrm{GmbH}$, designed to perform according to ASTM D-2892 requirements. The atmospheric residue from the TBP column was fractionated in a Potstill Euro Dist System according to ASTM D-5236 requirements. The density of the crude oils and their fractions was measured in accordance with ASTM D 4052. Sulphur content of the crude oils and their fractions was determined in accordance with ASTM D D4294. Pour point was determined in accordance with requirements of ASTM D 5853. Water and sediment content analyses were performed according to the procedures described in ASTM D 4006 and ASTM D 473 respectively. Method ASTM D 445 was applied to measure the crude oil kinematic viscosity. Chloride content was determined by applying the standard method ASTM D 3230. Acid number of crude oils was measured by potentiometric titration in accordance with ASTM D 664. SARA (saturates, aromatics, resins, asphaltenes) analysis of the crude oils was done by employing liquid chromatography following the procedure described in [50]. The methods used to characterize vacuum residue applied in the LNB refinery are explained in detail in our earlier studies [51-53].

For the purposes of defining the compatibility indices, solvent power and critical solvent power according to the procedure described in [42], the investigated crude oils and their blends with $n$-heptane were characterized for their distillation properties according to 
ASTM D 7169 (HTSD). These distillation characteristics along with density were employed to estimate the characterization factor (Kw) as shown in Equation (1).

$$
K w=\frac{\sqrt[3]{1.8\left[\frac{T 10+T 30+T 50+T 70+T 90}{5}+273.15\right]}}{d_{15}}
$$

Table 1 summarizes the properties of all crude oils investigated in the current study. The SARA analysis of the crude oils is shown in Table 2. Table 3 presents the properties of the crude oil fractions.

\subsection{N-Heptane Dilution Test}

The solutions of the selected crude oils and n-heptane were prepared at varying ratios between the crude oil and the normal paraffin. One sample tube contained $100 \mathrm{wt} . \%$ crude oil. The samples were thoroughly mixed and allowed to equilibrate and then centrifuged. The centrifuging process was carried out in a conventional centrifuge at $5000 \mathrm{rpm}$ for $30 \mathrm{~min}$. Supernatant oil liquid was removed from the centrifugal tube. The sediment was subsequently washed in $n$-heptane and dried. The drying process was carried out at $105^{\circ} \mathrm{C}$ for $8 \mathrm{~h}$. The recovered sediment was calculated in wt.\% of the base of crude oil and plotted against the weight percent of $n$-heptane of the solution of the particular sample tube.

\subsection{Compatibility Indices}

2.3.1. Crude oil Solvent Power and Critical Solvent Power

The solvent power of the crude oils was calculated as described in [42] and shown in Equation (2).

$$
S p=\frac{K c o-K h p}{K t-K h p} \times 100
$$

$K w$-characterization factor of $\mathrm{n}$-heptane $=12.72$ [54].

$K w$-characterization factor of toluene $=10.15$ [54].

The point of initial sediment precipitation, obtained from the n-heptane dilution test was used for determination of critical solvent power of the crude oil. Equation (2) is also used to estimate the critical solvent power. In that case, however, $K w$, characterization factor of the blend crude oil of n-heptane at the point of initial sediment precipitation, is used.

The solvent power of the petroleum blends was calculated by the use of Equation (3):

$$
\text { Sp blend }=\sum X i \times S p i
$$

The petroleum blend is considered compatible when its solvent power is greater than the critical solvent power of the crude oil having the highest critical solvent power in the blend.

\subsubsection{Compatibility Indices Based on Petroleum SARA Analysis Data}

Colloidal instability index (CII) was calculated by using Equation (4) and the SARA data of the studied crude oils.

$$
C I I=\frac{S a t+A s p}{A r o+R e s}
$$

In addition, the stability criteria expressed as ratios Sat/Aro and Res/Asp were estimated too. 
Table 1. Properties of investigated crude oils.

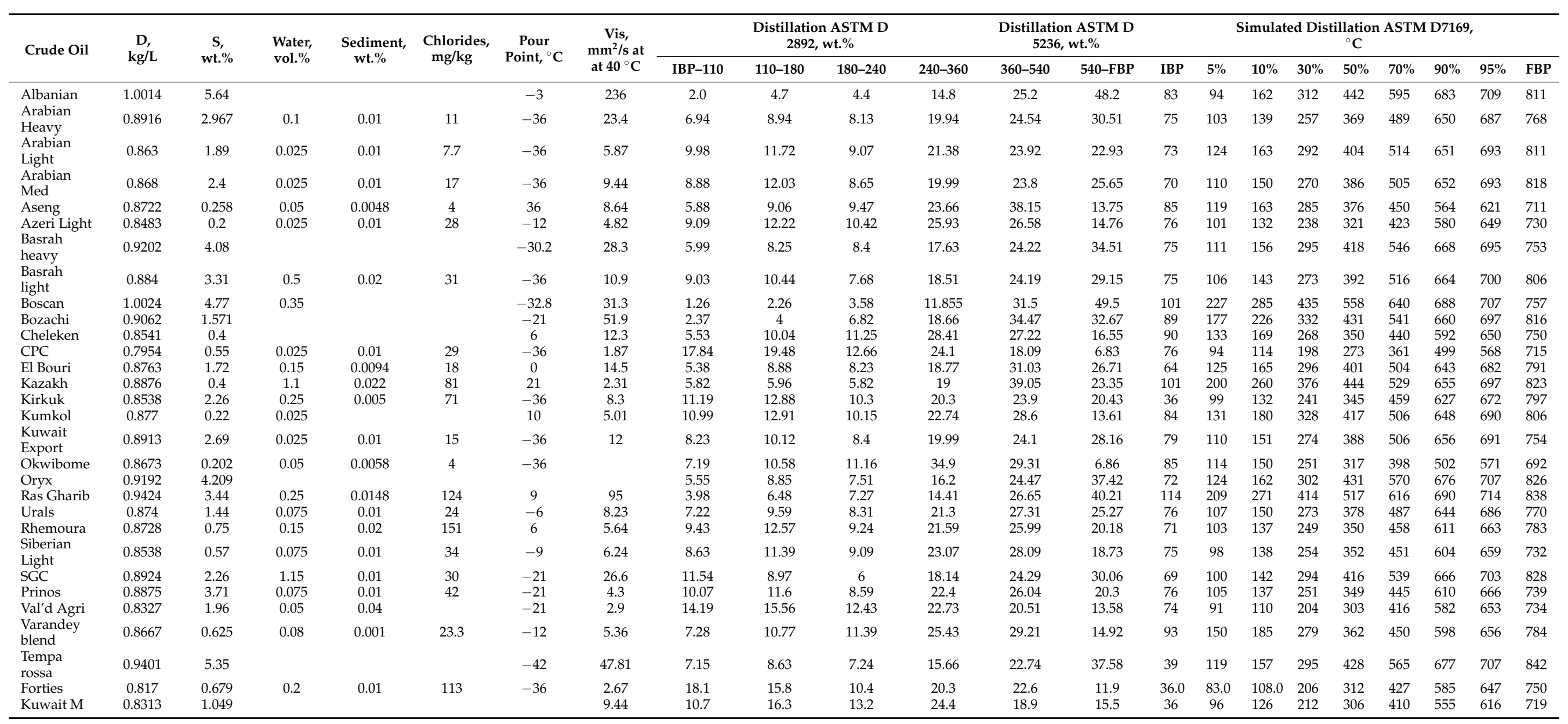


Table 2. Crude oil SARA analysis.

\begin{tabular}{|c|c|c|c|c|c|}
\hline Crude Oil & Sat, wt.\% & Aro, wt.\% & Res. wt.\% & $\begin{array}{c}\mathrm{C}_{7} \text { Asp., } \\
\text { wt.\% }\end{array}$ & $\begin{array}{c}\mathrm{C}_{5} \text { Asp. } \\
\text { wt. } \%\end{array}$ \\
\hline Albanian & 24.4 & 58.0 & 2.74 & 14.86 & 17.6 \\
\hline Arabian Heavy & 51.3 & 39.7 & 2.92 & 6.07 & 9.0 \\
\hline Arabian Light & 59.9 & 35.8 & 1.54 & 2.77 & 4.3 \\
\hline Arabian Medium & 58.4 & 35.1 & 2.79 & 3.74 & 6.5 \\
\hline Aseng & 57.1 & 42.4 & 0.06 & 0.51 & 0.4 \\
\hline Azeri Light & 64.6 & 34.6 & 0.60 & 0.20 & 0.8 \\
\hline Basrah heavy & 43.4 & 43.8 & 3.20 & 9.56 & 12.8 \\
\hline Basrah light & 53.5 & 38.4 & 2.82 & 5.25 & 8.1 \\
\hline Boscan & 24.2 & 57.5 & 4.72 & 13.61 & 18.3 \\
\hline Bozachi & 47.2 & 50.8 & 1.41 & 0.59 & 2.0 \\
\hline Cheleken & 62.7 & 35.2 & 1.11 & 0.95 & 2.1 \\
\hline СРC & 82.7 & 16.5 & 0.43 & 0.38 & 0.8 \\
\hline El Bouri & 55.8 & 36.9 & 2.61 & 4.67 & 7.3 \\
\hline Kazakh & 52.5 & 45.5 & 1.32 & 0.70 & 2.0 \\
\hline Kirkuk & 62.8 & 30.1 & 1.98 & 5.15 & 7.1 \\
\hline Kumkol & 55.6 & 44.3 & 0.07 & 0.05 & 0.1 \\
\hline Kuwait Export & 51.4 & 41.3 & 2.57 & 4.67 & 7.2 \\
\hline Okwibome & 58.6 & 41.3 & & 0.12 & \\
\hline Oryx & 43.7 & 44.8 & & 11.55 & \\
\hline Ras Gharib & 37.7 & 51.8 & & 10.45 & \\
\hline Urals & 56.5 & 39.0 & 0.88 & 3.56 & 4.4 \\
\hline Rhemoura & 56.9 & 36.8 & 1.63 & 4.68 & 6.3 \\
\hline Siberian Light & 62.8 & 34.3 & 1.44 & 1.46 & 2.9 \\
\hline SGC & 51.1 & 40.4 & 2.00 & 6.55 & 8.5 \\
\hline Prinos & 52.5 & 39.6 & 1.79 & 6.09 & 7.9 \\
\hline Val'd Agri & 69.7 & 27.6 & 1.50 & 1.15 & 2.7 \\
\hline Varandey blend & 58.8 & 39.2 & 0.87 & 1.14 & 2.0 \\
\hline Tempa rossa & 38.3 & 44.1 & 3.76 & 13.83 & 17.6 \\
\hline Forties & 75.1 & 23.8 & 0.31 & 0.86 & 1.2 \\
\hline Kuwait M & 70.2 & 27.2 & 1.00 & 1.60 & 2.6 \\
\hline
\end{tabular}

\subsubsection{Oil Compatibility Model}

Wiehe [26,27] first introduced the concept of oil compatibility model. It consists of defining the solubility and insolubility blending numbers and the ratio between them.

The ratio $S_{B N} / I_{N}$ (solubility blending number/insolubility number) was estimated using the information obtained from the n-heptane dilution test [10] and employing Equation (5) [55].

$$
\frac{S_{B N}}{I_{N}}=1+\frac{V h}{V o i l}
$$

where,

$V h$ is the maximum volume of n-heptane $(\mathrm{mL})$ at which the blend n-heptane-petroleum, where the crude oil volume is Voil $(\mathrm{mL})$, does not form a precipitation of asphaltenes.

$S_{B N}$ was calculated using the crude oil solubility parameter and solubility parameter of n-heptane and toluene (Equation (6)). The solubility parameters $(\delta)$ for toluene and $\mathrm{n}$-heptane were taken from literature [56] where $\delta T=18.3 \mathrm{MPa}{ }^{0.5}$ and $\delta H=15.2 \mathrm{MPa}^{0.5}$.

$$
S_{B N}=100\left[\frac{\delta c o-\delta H}{\delta T-\delta H}\right]
$$


Table 3. Properties of crude oil wide fractions.

\begin{tabular}{|c|c|c|c|c|c|c|c|c|c|c|c|c|c|c|c|c|}
\hline \multirow[b]{2}{*}{ Crude Oil } & \multicolumn{2}{|c|}{ IBP-110 } & \multicolumn{2}{|c|}{ 110-180 } & \multicolumn{2}{|c|}{ 180-240 } & \multicolumn{2}{|c|}{$240-360$} & \multicolumn{2}{|c|}{$360-540$} & \multicolumn{6}{|c|}{ 540-FBP } \\
\hline & $\begin{array}{c}\mathrm{D}, \\
\mathrm{kg} / \mathrm{L}\end{array}$ & $\begin{array}{c}\text { S, } \\
\text { wt.\% }\end{array}$ & $\underset{\mathrm{kg} / \mathrm{L}}{\mathrm{D}}$ & $\begin{array}{r}\text { S, } \\
\text { wt. } \%\end{array}$ & $\underset{\mathrm{kg} / \mathrm{L}}{\mathrm{D}}$ & $\begin{array}{r}\text { S, } \\
\text { wt. } \%\end{array}$ & $\underset{\mathrm{kg} / \mathrm{L}}{\mathrm{D}}$ & $\begin{array}{r}\text { S, } \\
\text { wt. } \%\end{array}$ & $\begin{array}{c}\mathrm{D}, \\
\mathrm{kg} / \mathrm{L}\end{array}$ & $\begin{array}{c}\mathbf{S}, \\
\text { wt.\% }\end{array}$ & $\begin{array}{c}\mathrm{D}, \\
\mathrm{kg} / \mathrm{L}\end{array}$ & $\begin{array}{c}\text { S, } \\
\text { wt.\% }\end{array}$ & $\begin{array}{c}\mathrm{C}_{7} A s p \\
\text { w..\% }\end{array}$ & $\begin{array}{c}\mathrm{C}_{5} A s p \\
\text { w..\% }\end{array}$ & $\begin{array}{l}\text { CCR, } \\
\text { wt.\% }\end{array}$ & $\begin{array}{c}V i s, \\
\mathrm{~mm}^{2} / \mathrm{s}\end{array}$ \\
\hline Albanian & 0.690 & 0.29 & 0.7902 & 1.05 & 0.850 & 1.99 & 0.913 & 3.69 & 0.986 & 5.59 & 1.080 & & 30.8 & 36.5 & 24.2 & \\
\hline Arabian Heavy & 0.679 & 0.03 & 0.755 & 0.07 & 0.800 & 0.34 & 0.863 & 2.01 & 0.927 & 3.23 & 1.026 & 5.82 & 19.9 & 29.5 & & \\
\hline Arabian Light & 0.677 & 0.09 & 0.758 & 0.14 & 0.799 & 0.25 & 0.851 & 1.36 & 0.919 & 2.51 & 1.004 & 4.86 & 12.1 & 18.8 & & \\
\hline Arabian Medium & 0.701 & 0.07 & 0.768 & 0.13 & 0.802 & 0.31 & 0.854 & 1.55 & 0.915 & 2.75 & 1.005 & 5.27 & 14.6 & 25.5 & 20.7 & \\
\hline Aseng & 0.725 & 0.08 & 0.787 & 0.10 & 0.830 & 0.16 & 0.862 & 0.27 & 0.818 & 0.29 & 1.002 & 0.62 & 3.7 & 3.3 & 14.2 & 28 \\
\hline Azeri Light & 0.734 & 0.06 & 0.779 & 0.07 & 0.815 & 0.07 & 0.851 & 0.14 & 0.901 & 0.25 & 0.959 & 0.54 & 1.4 & 5.4 & 9.5 & 19 \\
\hline Basrah heavy & 0.693 & 0.03 & 0.760 & 0.18 & 0.804 & 0.55 & 0.878 & 2.70 & 0.947 & 4.30 & 1.045 & 7.36 & 27.7 & 37.0 & 28.9 & \\
\hline Basrah light & 0.709 & 0.06 & 0.768 & 0.18 & 0.803 & 0.43 & 0.858 & 1.96 & 0.937 & 3.94 & 1.006 & 6.14 & 18.0 & 27.7 & 23.8 & \\
\hline Boscan & 0.725 & 0.13 & 0.752 & 0.64 & 0.824 & 2.29 & 0.891 & 3.83 & 0.953 & 4.73 & 1.072 & & 27.5 & 37.0 & 20.8 & 1028 \\
\hline Bozachi & 0.721 & 0.01 & 0.777 & 0.04 & 0.817 & 0.19 & 0.853 & 0.75 & 0.910 & 1.42 & 1.006 & 3.10 & 1.8 & 6.1 & 16.0 & \\
\hline Cheleken & 0.716 & 0.08 & 0.765 & 0.09 & 0.802 & 0.11 & 0.836 & 0.22 & 0.886 & 0.42 & 0.974 & 1.20 & 5.8 & 12.5 & & \\
\hline СРC & 0.702 & 0.15 & 0.771 & 0.28 & 0.807 & 0.26 & 0.846 & 0.76 & 0.891 & 1.16 & 0.931 & 1.32 & 5.6 & 11.9 & 9.2 & \\
\hline El Bouri & 0.711 & 0.01 & 0.774 & 0.04 & 0.817 & 0.17 & 0.861 & 1.24 & 0.910 & 1.90 & 1.040 & 3.37 & 17.5 & 27.3 & 25.47 & 139 \\
\hline Kazakh & 0.710 & 0.03 & 0.768 & 0.02 & 0.808 & 0.05 & 0.851 & 0.21 & 0.893 & 0.36 & 1.009 & 0.94 & 3.0 & 8.7 & 10.9 & 17 \\
\hline Kirkuk & 0.682 & 0.05 & 0.758 & 0.10 & 0.797 & 0.20 & 0.853 & 1.45 & 0.920 & 2.81 & 1.040 & 6.22 & 25.2 & 34.9 & & \\
\hline Kumkol & 0.687 & 0.011 & 0.7632 & 0.02 & 0.801 & 0.04 & 0.830 & 0.10 & 0.875 & 0.21 & 0.952 & 0.53 & 0.37 & 0.92 & & \\
\hline Kuwait Export & 0.697 & 0.06 & 0.764 & 0.10 & 0.800 & 0.27 & 0.856 & 1.68 & 0.920 & 2.99 & 1.007 & 5.68 & 16.6 & 25.7 & & \\
\hline Okwibome & 0.712 & 0.07 & 0.763 & 0.08 & 0.818 & 0.10 & 0.877 & 0.19 & 0.931 & 0.29 & 0.998 & 0.50 & 1.7 & & 12.9 & 9 \\
\hline Oryx & 0.686 & 0.00 & 0.752 & 0.06 & 0.793 & 0.33 & 0.852 & 1.94 & 0.932 & 3.80 & 1.084 & 8.01 & 30.9 & & 29.41 & 564 \\
\hline Ras Gharib & 0.700 & 0.06 & 0.767 & 0.35 & 0.816 & 1.02 & 0.863 & 2.31 & 0.921 & 3.02 & 1.063 & 5.58 & 26.0 & & 25.1 & 430 \\
\hline Urals & 0.724 & 0.07 & 0.774 & 0.15 & 0.812 & 0.30 & 0.856 & 0.94 & 0.907 & 1.61 & 1.003 & 2.93 & 14.1 & 17.6 & 17.5 & \\
\hline Rhemoura & 0.725 & 0.05 & 0.777 & 0.06 & 0.817 & 0.10 & 0.854 & 0.52 & 0.910 & 0.97 & 1.006 & 1.90 & 23.2 & 31.3 & 23.7 & \\
\hline Siberian Light & 0.715 & 0.03 & 0.775 & 0.06 & 0.814 & 0.10 & 0.855 & 0.35 & 0.905 & 0.78 & 1.005 & 1.58 & 7.8 & 15.5 & 14.0 & \\
\hline South Green Canyon & 0.714 & 0.06 & 0.776 & 0.14 & 0.813 & 0.34 & 0.863 & 1.17 & 0.927 & 2.22 & 1.007 & 5.09 & 21.8 & 28.4 & 22.9 & \\
\hline Prinos & 0.704 & 0.17 & 0.788 & 0.40 & 0.821 & 0.72 & 0.867 & 2.61 & 0.942 & 3.90 & 1.039 & 9.14 & 30.0 & 38.8 & 32.82 & \\
\hline Val'd Agri & 0.683 & 0.04 & 0.761 & 0.07 & 0.802 & 0.29 & 0.862 & 1.73 & 0.935 & 3.29 & 0.999 & 6.47 & 8.5 & 19.5 & 21.4 & 80 \\
\hline Varandey blend & 0.716 & 0.02 & 0.772 & 0.09 & 0.809 & 0.15 & 0.850 & 0.48 & 0.888 & 0.74 & 0.987 & 1.76 & 7.62 & 13.48 & 15.1 & 24.25 \\
\hline Tempa rossa & 0.682 & 0.07 & 0.76 & 0.42 & 0.807 & 1.14 & 0.883 & 3.58 & 0.970 & 5.10 & 1.119 & 9.26 & 36.8 & 46.8 & 34.33 & \\
\hline Forties & 0.696 & 0.05 & 0.8 & 0.07 & 0.805 & 0.11 & 0.848 & 0.48 & 0.971 & 1.51 & 0.989 & 2.54 & 7.2 & 9.8 & 14.77 & \\
\hline Kuwait M & 0.680 & 0.05 & 0.755 & 0.066 & 0.795 & 0.09 & 0.847 & 0.86 & 0.912 & 1.86 & & & & & & \\
\hline
\end{tabular}


Solubility parameter of the crude oil was calculated on the basis of the crude oil density and the correlation of Correra et al. [57] and shown as Equation (7).

$$
\delta c o=24.042 \times d^{0.5}-4.5989
$$

Solubility blending number of the petroleum blends is the volumetric average for those oils [47] and was estimated by applying Equation (8).

$$
S_{B N m i x}=\frac{\sum V_{i} \times S_{B N i}}{\sum V_{i}}
$$

Table 4 summarizes all the compatibility indices employed in this work for all the studied crude oils.

\begin{tabular}{|c|c|c|c|c|c|c|c|c|c|}
\hline Crude Oil & $S p$ & $\begin{array}{c}S p \\
\text { Critical }\end{array}$ & CII & Sat/Aro & $\operatorname{Res} / A s p$ & $\begin{array}{c}\delta_{C O} \\
\mathrm{MPa}^{0.5}\end{array}$ & $S_{B N} / I_{N}$ & $S_{B N}$ & $I_{N}$ \\
\hline Albanian & 94.1 & 52.2 & 0.65 & 0.4 & 0.2 & 19.44 & 1.00 & 136.7 & 136.7 \\
\hline $\begin{array}{l}\text { Arabian } \\
\text { Heavy }\end{array}$ & 60.3 & 34.4 & 1.35 & 1.3 & 0.5 & 18.07 & 2.31 & 92.4 & 40.0 \\
\hline Arabian Light & 36.5 & 27.8 & 1.68 & 1.7 & 0.6 & 17.69 & 1.55 & 80.5 & 51.9 \\
\hline $\begin{array}{l}\text { Arabian } \\
\text { Medium }\end{array}$ & 44.0 & 38.6 & 1.64 & 1.7 & 0.7 & 17.76 & 1.86 & 82.6 & 44.4 \\
\hline Aseng & 44.1 & 29.1 & 1.36 & 1.3 & 0.1 & 17.81 & 1.86 & 84.3 & 45.3 \\
\hline Azeri Light & 44.2 & 37.6 & 1.84 & 1.9 & 3.0 & 17.50 & 1.33 & 74.2 & 55.8 \\
\hline Basrah heavy & 63.9 & 46.4 & 1.13 & 1.0 & 0.3 & 18.43 & 1.90 & 104.2 & 54.8 \\
\hline Basrah light & 52.7 & 36.5 & 1.43 & 1.4 & 0.5 & 17.97 & 1.87 & 89.3 & 47.7 \\
\hline Boscan & 68.9 & 48.2 & 0.61 & 0.4 & 0.3 & 19.45 & 1.00 & 137.0 & 137.0 \\
\hline Bozachi & 45.2 & 36.9 & 0.92 & 0.9 & 2.4 & 18.25 & 2.33 & 98.5 & 42.3 \\
\hline Cheleken & 37.5 & 25.3 & 1.75 & 1.8 & 1.2 & 17.58 & 2.24 & 76.7 & 34.2 \\
\hline $\mathrm{CPC}$ & 24.2 & 31.2 & 4.92 & 5.0 & 1.1 & 16.79 & 1.00 & 51.4 & 51.4 \\
\hline El Bouri & 43.3 & 41.4 & 1.53 & 1.5 & 0.6 & 17.87 & 1.34 & 86.1 & 64.2 \\
\hline Kazakh & 29.6 & 19.4 & 1.14 & 1.2 & 1.9 & 18.01 & 1.55 & 90.8 & 58.6 \\
\hline Kirkuk & 45.4 & 42.0 & 2.12 & 2.1 & 0.4 & 17.57 & 1.31 & 76.6 & 58.5 \\
\hline Kumkol & 38.9 & 38.2 & 1.26 & 1.3 & 1.5 & 17.88 & 1.14 & 86.4 & 75.8 \\
\hline $\begin{array}{l}\text { Kuwait } \\
\text { Export }\end{array}$ & 55.4 & 42.0 & 1.28 & 1.2 & 0.6 & 18.06 & 1.88 & 92.3 & 49.1 \\
\hline Okwibome & 50.1 & 31.6 & 1.42 & 1.4 & & 17.75 & 1.85 & 82.3 & 44.5 \\
\hline Oryx & 60.6 & 50.1 & 1.23 & 1.0 & & 18.42 & 1.58 & 103.8 & 65.7 \\
\hline Ras Gharib & 47.0 & 22.2 & 0.93 & 0.7 & & 18.71 & 1.61 & 113.2 & 70.3 \\
\hline Urals & 48.1 & 32.5 & 1.51 & 1.4 & 0.2 & 17.84 & 1.88 & 85.1 & 45.3 \\
\hline Rhemoura & 52.9 & 41.2 & 1.60 & 1.5 & 0.3 & 17.82 & 1.32 & 84.6 & 64.1 \\
\hline Siberian Light & 42.6 & 29.0 & 1.80 & 1.8 & 1.0 & 17.57 & 2.26 & 76.6 & 33.9 \\
\hline $\begin{array}{l}\text { South Green } \\
\text { Canyon }\end{array}$ & 53.3 & 38.4 & 1.36 & 1.3 & 0.3 & 18.08 & 1.88 & 92.8 & 49.3 \\
\hline Prinos & 60.8 & 39.3 & 1.42 & 1.3 & 0.3 & 18.01 & 1.34 & 90.7 & 67.7 \\
\hline Val'd Agri & 43.6 & 28.2 & 2.43 & 2.5 & 1.3 & 17.30 & 2.22 & 67.6 & 30.4 \\
\hline $\begin{array}{l}\text { Varandey } \\
\text { blend }\end{array}$ & 40.2 & 36.9 & 1.49 & 1.5 & 0.8 & 17.74 & 1.32 & 82.0 & 62.1 \\
\hline Tempa rossa & 71.73 & 60.97 & 1.09 & 0.9 & 0.3 & 18.68 & 1.59 & 112.3 & 70.6 \\
\hline Forties & 37.83 & 18.73 & 3.15 & 3.2 & 0.4 & 17.09 & 1.99 & 60.8 & 30.6 \\
\hline Kuwait M & 37.67 & 37.67 & 2.54 & 2.6 & 0.6 & 17.28 & 1.0 & 66.98 & 66.98 \\
\hline
\end{tabular}

Table 4. Crude oil compatibility indices.

\section{Results}

\subsection{Relations between Compatibility Indices and Crude Oil Properties}

The experimental strategy presented in the current study to determine the compatibility indices was accomplished in three stages explained below: (1) Preparing mixtures of crude oil with n-heptane at different ratios; (2) determination of the onset of asphaltene precipitation; (3) estimation of compatibility indices. Crude oils, investigated in this study, exhibited different behaviors during the dilution with n-heptane. Figure 1 presents three typical graphs of relation of recovered sediment to the n-heptane content in the crude oil-n-heptane mixture. Most crude oils have behavior similar to that shown in Figure 1a. Recovered sediment starts to increase rapidly at a given n-heptane concentration for each 
oil sample and this threshold is called initial sediment precipitation. As explained before the initial sediment precipitation is used to estimate the crude oil solvent power and critical solvent power by the use of Equations (1) and (2). Most of the studied crude oils had solvent power below 60 and they could be classified as cyclohexane equivalent [28]. Crude oil with solvent power of zero is equivalent to n-heptane, and a crude oil with a solvent power of one hundred is equivalent to toluene [42]. Some of the light crude oils with solvent power less than 44 and characterization factor $K w$ in the range 11.8-12.2 showed behavior similar to that presented in Figure $1 \mathrm{~b}, \mathrm{c}$. These light crude oils can be considered as self-incompatible or near-incompatible [27]. Recovered sediment can decrease or remain unchanged with increasing the quantity of n-heptane in the blend crude oil-n-heptane. In our study crude oils with low asphaltene and high paraffinic content such as CPC, Kuwait M, Azeri light demonstrated the behavior shown in Figure 1b,c during the nheptane dilution process. It is well-known that the sediment recovered during the crude oil centrifuging process can be classified as inorganic and organic. Inorganic sediment is represented by suspended impurities, such as sand, dirt, clay, or rust coming from the crude oil production process $[13,55]$. Organic sediments include asphaltenes, and high molecular waxes $[13,55,58]$. Sediment decreasing during the n-heptane dilution process of Kuwait $\mathrm{M}$ crude oil might be a result of the mutual dissolving of waxes and asphaltenes. Waxes can improve dissolution of asphaltenes because of the interaction between side alkyl chains in asphaltenes and waxes [55,58-62]. The dissolution of the solids is accelerated because of increasing volume of alkyl layers surrounding the asphaltenes polyaromatic cores [60]. That is why, the proper determination of flocculation point of the mentioned above light paraffinic low asphaltenes crude oils is very difficult and even impossible. Their solubility power is close to that of the n-heptane. Additional in-depth study is required to generate correct results for the compatibility indices based on the n-heptane dilution test $[10,26]$.

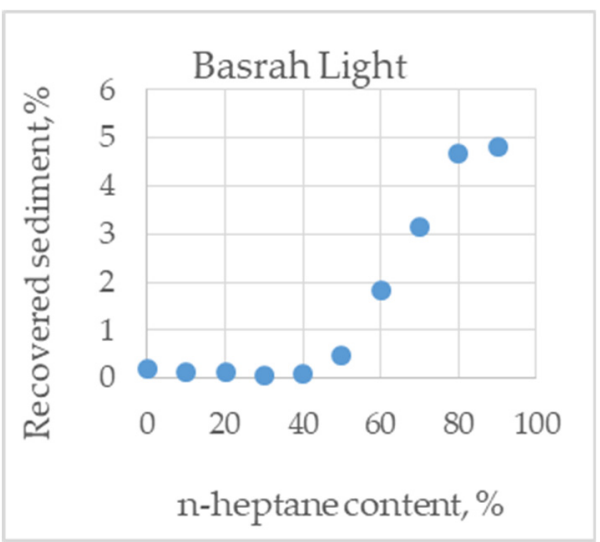

(a)

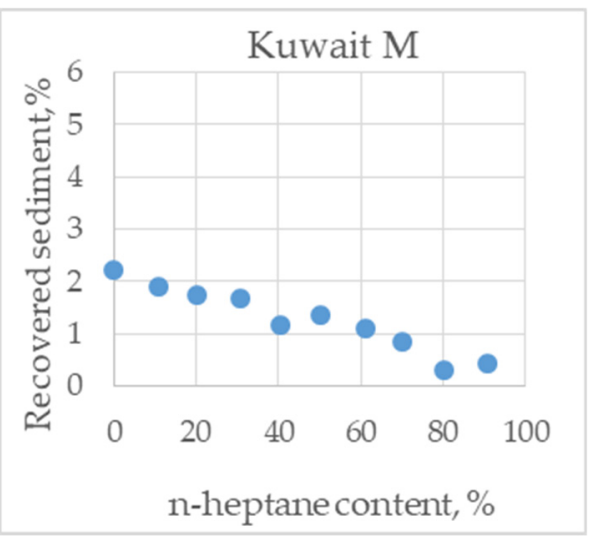

(b)

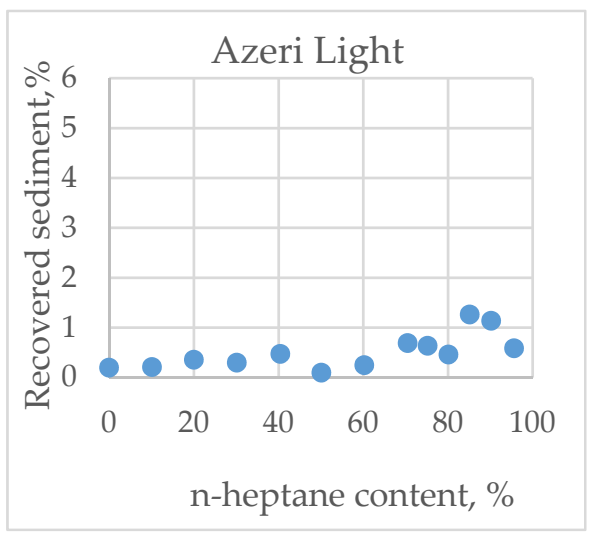

(c)

Figure 1. Dependence of crude sediment content on the concentration of n-heptane in the blend crude oil-n-heptane for light crude oils: (a) Basrah Light crude oil; (b) Kuwait M crude oil; (c) Azeri Light crude oil.

The relations between different crude oil properties and measured compatibility indices shown in Tables 1-4 were examined by using the intercriteria analysis (ICrA). The ICrA approach is specifically designed for datasets comprising evaluations, or measurements of multiple objects against multiple criteria. In the initial formulation of the method, the aim was to detect statistically meaningful relations between the criteria, in order to eliminate future evaluations/measurements against some of the criteria, which exhibit high enough correlations with others. The reader can find more information concerning the application of ICrA in our recent studies and the references there [17,63]. ICrA defines the relations between the studied criteria (parameters) in terms of intuitionistic fuzzy pairs $\langle\mu, v\rangle[17,63]$. Depending on the values of $\mu$ and $v$ seen in pair, positive consonance, negative consonance, and dissonance between any pair of criteria (parameters) can be defined. 
Values of $\mu=0.75 \div 1.00$ and $\nu=0.00 \div 0.25$ denote a statistically meaningful positive relation, where the strong positive consonance is exhibited at values of $\mu=0.95 \div 1.00$, $v=0.00 \div 0.05$ and the weak positive consonance is exhibited at values of $\mu=0.75 \div 0.85$, $v=0.15 \div 0.25$. Respectively, the values of negative consonance with $\mu=0.00 \div 0.25$ and $v=0.75 \div 1.05$ represent a statistically meaningful negative relation, where the strong negative consonance exhibits values of $\mu=0.00 \div 0.05, v=0.95 \div 1.00$ and the weak negative consonance exhibits values of $\mu=0.15 \div 0.25, v=0.15 \div 0.25$. All other cases are characterized as dissonance $[17,63]$.

Table 5 presents the $\mu$ values of ICrA of the different compatibility indices summarized in Table 4. It is evident from the data in Table 5 that the solvent power of the crude oil weakly positively correlates $(\mu=0.81)$ with the solubility parameter and solubility blending number. The solubility blending number negatively weakly correlates with CII and ratio Sat / Aro $(\mu=0.20$ and $\mu=0.16$ respectively).

Table 5. $\mu$-value of the ICrA evaluation of relations between different compatibility indices.

\begin{tabular}{cccccccccc}
\hline $\boldsymbol{\mu}$ & $\boldsymbol{S} \boldsymbol{p}$ & $\begin{array}{c}S \boldsymbol{p} \\
\text { Critical }\end{array}$ & $\boldsymbol{C I I}$ & Sat/Aro & Res/Asp & $\delta_{\text {CO }}$ & $S_{B N} / \mathbf{I}_{\boldsymbol{N}}$ & $\boldsymbol{S}_{\boldsymbol{B N}}$ & $\boldsymbol{I}_{\boldsymbol{N}}$ \\
\hline Sp & 1.00 & 0.79 & 0.40 & 0.36 & 0.57 & 0.81 & 0.48 & 0.81 & 0.62 \\
Sp critical & 0.79 & 1.00 & 0.64 & 0.60 & 0.71 & 0.57 & 0.34 & 0.57 & 0.57 \\
CII & 0.40 & 0.64 & 1.00 & 0.99 & 0.51 & 0.20 & 0.38 & 0.20 & 0.59 \\
Sat/Aro & 0.36 & 0.60 & 0.99 & 1.00 & 0.63 & 0.16 & 0.41 & 0.16 & 0.56 \\
Res $/$ Asp & 0.57 & 0.71 & 0.51 & 0.63 & 1.00 & 0.74 & 0.51 & 0.24 & 0.29 \\
$\delta_{C O}$ & 0.81 & 0.57 & 0.20 & 0.16 & 0.74 & 1.00 & 0.33 & 0.99 & 0.75 \\
$S_{B N} / I_{N}$ & 0.48 & 0.34 & 0.38 & 0.41 & 0.51 & 0.33 & 1.00 & 0.33 & 0.28 \\
$S_{B N}$ & 0.81 & 0.57 & 0.20 & 0.16 & 0.24 & 0.99 & 0.33 & 1.00 & 0.75 \\
$I_{N}$ & 0.62 & 0.57 & 0.59 & 0.56 & 0.29 & 0.75 & 0.28 & 0.75 & 1.00 \\
\hline
\end{tabular}

Note: Green color means statistically meaningful positive relation; Red color implies statistically meaningful negative relation. The intensity of the color designates the strength of the relation. The higher the color intensity, the higher the strength of the relation is. Yellow color denotes dissonance.

Figure 2 presents the discussed relations. Solubility power and critical solubility power increase with and increase in $S_{B N}$ (Figure 2a). The relation between $S_{B N}$ and CII can be described by a power function (Figure 2a) with a squared correlation coefficient of $\mathrm{R}^{2}=0.978$. The relation between solubility parameter and Sat/Aro ratio can be also described by a power function with a squared correlation coefficient $R^{2}=0.938$. The compatibility indices solubility parameter, $S_{B N}$ and solvent power correlate with density $[28,46]$. The content of saturates and aromatics in the crude oil and its fractions also correlates with density [63]. Therefore, the presence of a statistically meaningful relation between solubility blending number, for example, and the indices determined based on SARA analysis data can be expected. Indeed, this is confirmed by the data shown in Figure 2b,c.

The ICrA examination of the data in Table 6 revealed that the solvent power had a weak statistically meaningful relation with the density, sulfur and asphaltene content in the crude oil. Figure 3 depicts the relations between solvent power and crude oil density (a) and sulfur content (b). The asphaltene content in the crude oil was also found to relate to the solvent and critical solvent power (Figure 4). The $C_{5}$ asphaltene content was found to have a bigger impact on the solvent power than the $C_{7}$ asphaltene content. In general, the heavy crude oils, which have higher contents of sulfur, polar aromatics, and asphaltenes exhibit higher solubility power because the polar aromatic compounds (resins) in the crude oil are stabilizing agents that prevent the asphaltene precipitation [64]. Respectively, the crude oils, which have higher saturate (low density) and lower asphaltene contents, can be colloidal instable and they are more susceptible to cause sediment deposition during the petroleum exploration and processing [65]. 


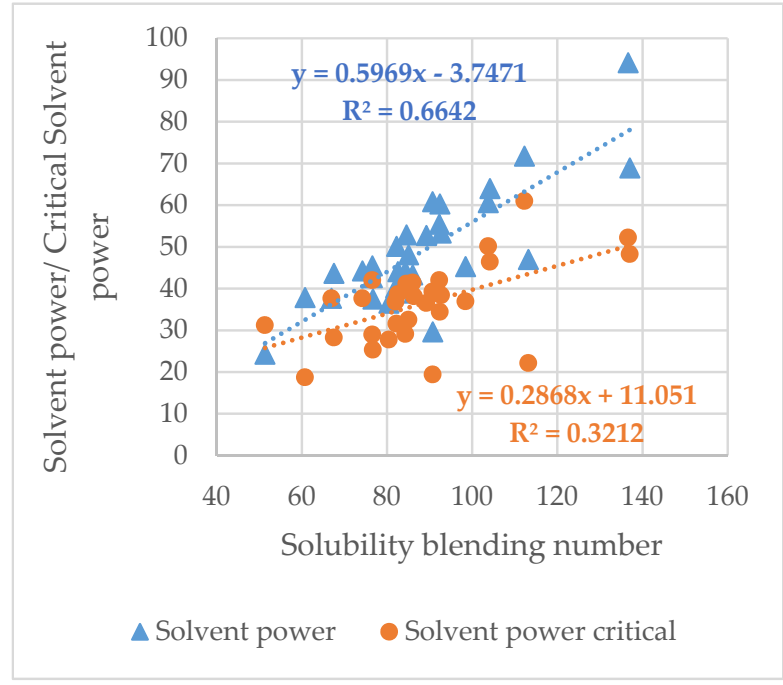

(a)

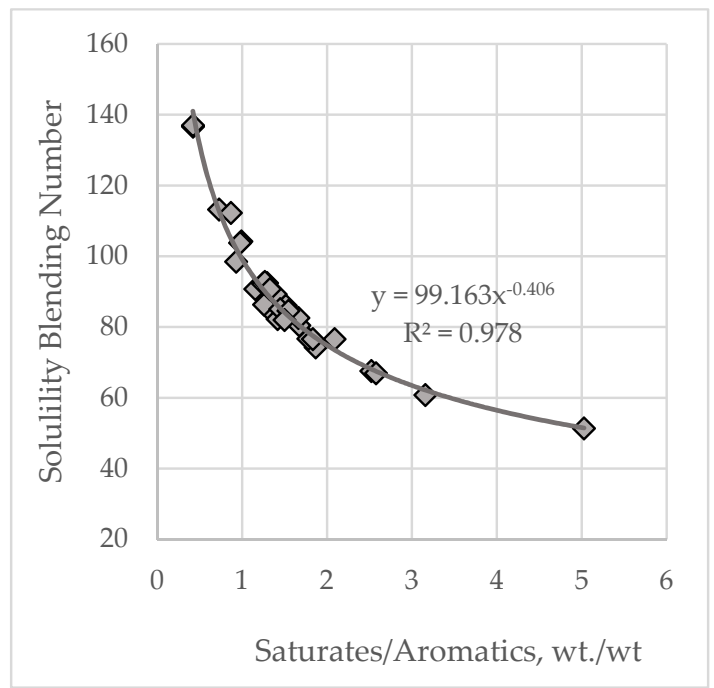

(b)

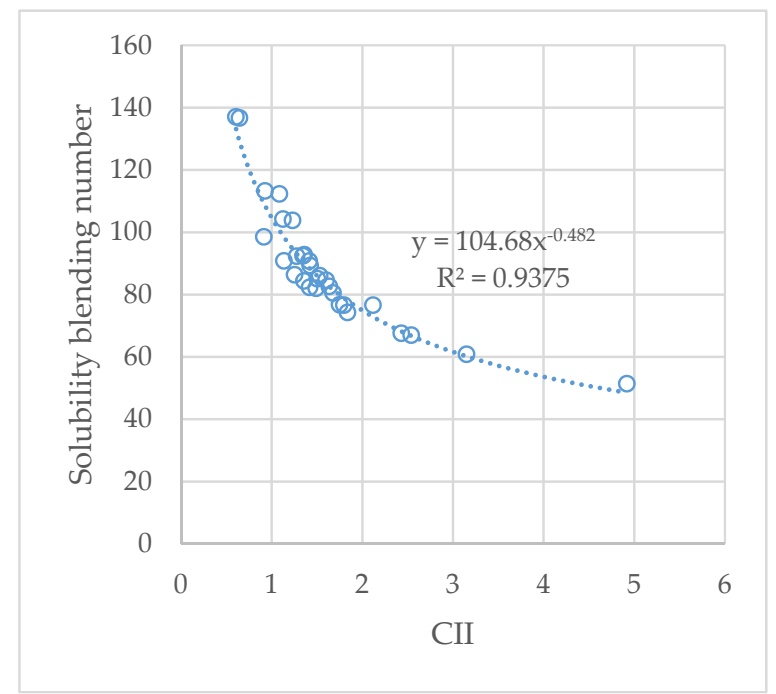

(c)

Figure 2. Dependences of compatibility indices: (a) relation between $S_{B N}$ and $S p$ and $S p$ critical; (b) relation between $S_{B N}$ and ratio Sar/Aro; (c) relation between $S_{B N}$ and CII.

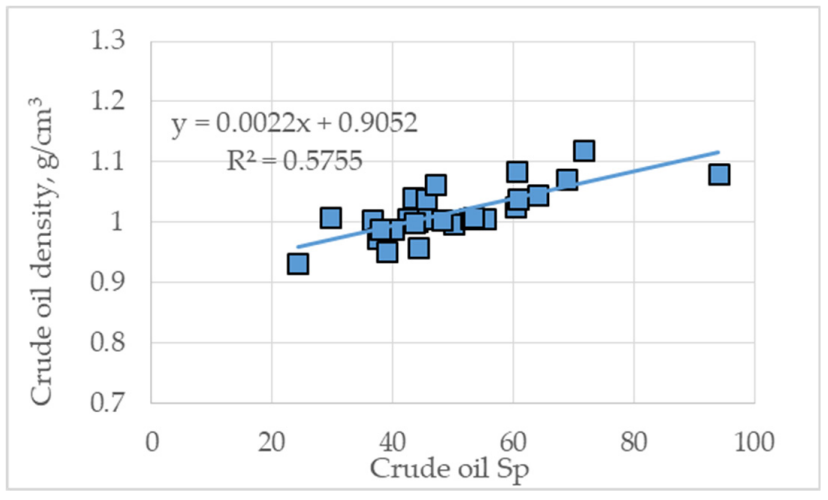

(a)

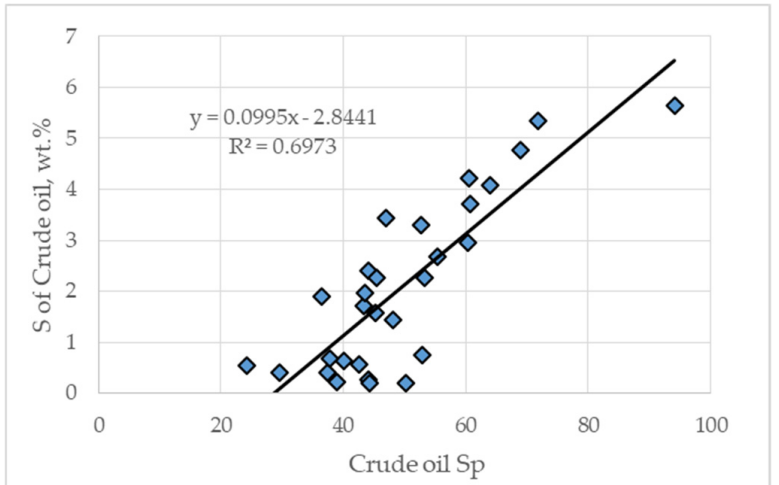

(b)

Figure 3. Dependence of solvent power on density (a) and sulfur content (b) of the studied crude oils. 
Table 6. $\mu$-value of the ICrA evaluation of relations between some compatibly indices and properties of the studied crude oils of different origins.

\begin{tabular}{|c|c|c|c|c|c|c|c|c|c|c|c|c|c|c|}
\hline$\mu$ & $\begin{array}{l}\text { Density } \\
\text { at } 15^{\circ} \mathrm{C}\end{array}$ & Sulfur & $\begin{array}{l}\text { Pour } \\
\text { Point }\end{array}$ & $S p$ & $\begin{array}{c}S p \\
\text { Critical }\end{array}$ & Vis & $\begin{array}{c}\mathrm{C}_{7} \text { Asp. } \\
\mathrm{CO}\end{array}$ & $\begin{array}{c}\mathrm{C}_{5} A s p . \\
\mathrm{CO}\end{array}$ & $S_{B N} / I_{N}$ & TAN & $\begin{array}{c}\text { Density } \\
\text { VR }\end{array}$ & $\begin{array}{c}\text { Sulfur } \\
\text { VR }\end{array}$ & $\begin{array}{c}\mathrm{C}_{7} A s p . \\
\text { VR }\end{array}$ & $\underset{\text { VR }}{\mathrm{C}_{5} A s p .}$ \\
\hline Density at $15^{\circ} \mathrm{C}$ & 1.00 & 0.73 & 0.44 & 0.78 & 0.72 & 0.79 & 0.76 & 0.76 & 0.50 & 0.56 & 0.78 & 0.69 & 0.70 & 0.69 \\
\hline Sulfur & 0.73 & 1.00 & 0.24 & 0.81 & 0.74 & 0.74 & 0.88 & 0.87 & 0.48 & 0.45 & 0.82 & 0.95 & 0.86 & 0.86 \\
\hline Pour Point & 0.44 & 0.24 & 1.00 & 0.35 & 0.38 & 0.41 & 0.32 & 0.30 & 0.40 & 0.54 & 0.36 & 0.25 & 0.33 & 0.30 \\
\hline$S p$ & 0.78 & 0.81 & 0.35 & 1.00 & 0.79 & 0.76 & 0.83 & 0.81 & 0.48 & 0.50 & 0.80 & 0.78 & 0.81 & 0.79 \\
\hline Sp critical & 0.72 & 0.74 & 0.38 & 0.79 & 1.00 & 0.71 & 0.74 & 0.73 & 0.34 & 0.53 & 0.76 & 0.72 & 0.75 & 0.75 \\
\hline Vis & 0.79 & 0.74 & 0.41 & 0.76 & 0.71 & 1.00 & 0.76 & 0.77 & 0.57 & 0.51 & 0.75 & 0.70 & 0.72 & 0.69 \\
\hline $\mathrm{C}_{7}$ Asp. $\mathrm{CO}$ & 0.76 & 0.88 & 0.32 & 0.83 & 0.74 & 0.76 & 1.00 & 0.94 & 0.46 & 0.48 & 0.85 & 0.86 & 0.94 & 0.92 \\
\hline $\mathrm{C}_{5}$ Asp. $\mathrm{CO}$ & 0.76 & 0.87 & 0.30 & 0.81 & 0.73 & 0.77 & 0.94 & 1.00 & 0.47 & 0.47 & 0.84 & 0.84 & 0.89 & 0.89 \\
\hline$S_{B N} / I_{N}$ & 0.50 & 0.48 & 0.40 & 0.48 & 0.34 & 0.57 & 0.46 & 0.47 & 1.00 & 0.33 & 0.46 & 0.49 & 0.42 & 0.43 \\
\hline TAN & 0.56 & 0.45 & 0.54 & 0.50 & 0.53 & 0.51 & 0.48 & 0.47 & 0.33 & 1.00 & 0.44 & 0.43 & 0.47 & 0.46 \\
\hline Density VR & 0.78 & 0.82 & 0.36 & 0.80 & 0.76 & 0.75 & 0.85 & 0.84 & 0.46 & 0.44 & 1.00 & 0.81 & 0.84 & 0.82 \\
\hline Sulfur VR & 0.69 & 0.95 & 0.25 & 0.78 & 0.72 & 0.70 & 0.86 & 0.84 & 0.49 & 0.43 & 0.81 & 1.00 & 0.86 & 0.86 \\
\hline $\mathrm{C}_{7}$ Asp. VR & 0.70 & 0.86 & 0.33 & 0.81 & 0.75 & 0.72 & 0.94 & 0.89 & 0.42 & 0.47 & 0.84 & 0.86 & 1.00 & 0.96 \\
\hline $\mathrm{C}_{5}$ Asp. VR & 0.69 & 0.86 & 0.30 & 0.79 & 0.75 & 0.69 & 0.92 & 0.89 & 0.43 & 0.46 & 0.82 & 0.86 & 0.96 & 1.00 \\
\hline
\end{tabular}

Note: Green color means statistically meaningful positive relation; Red color implies statistically meaningful negative relation. The intensity of the color designates the strength of the relation. The higher the color intensity, the higher the strength of the relation is. Yellow color denotes dissonance.

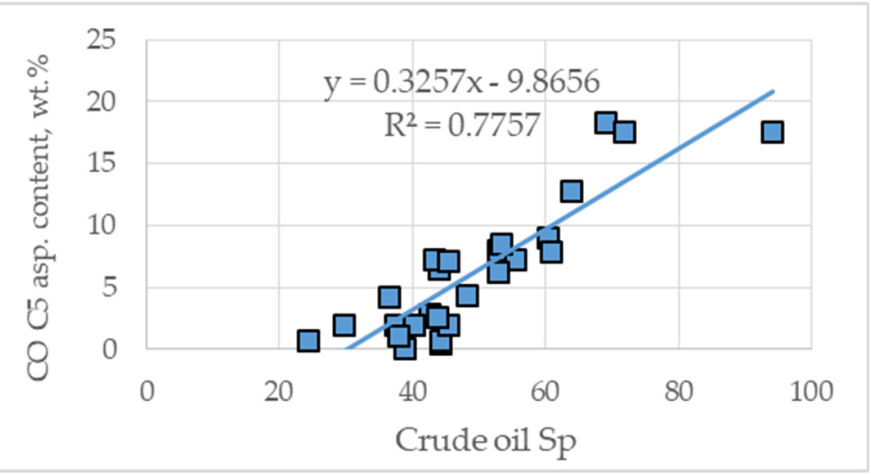

(a)

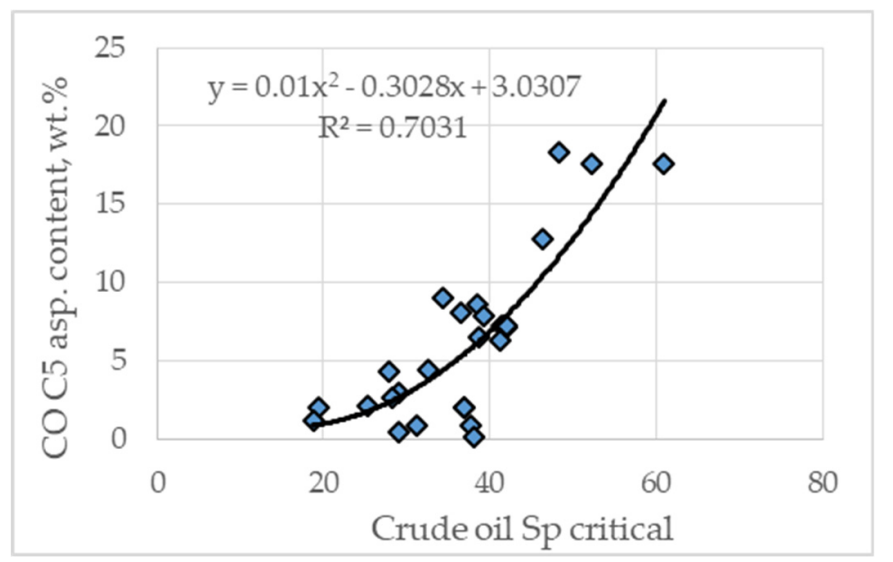

(c)

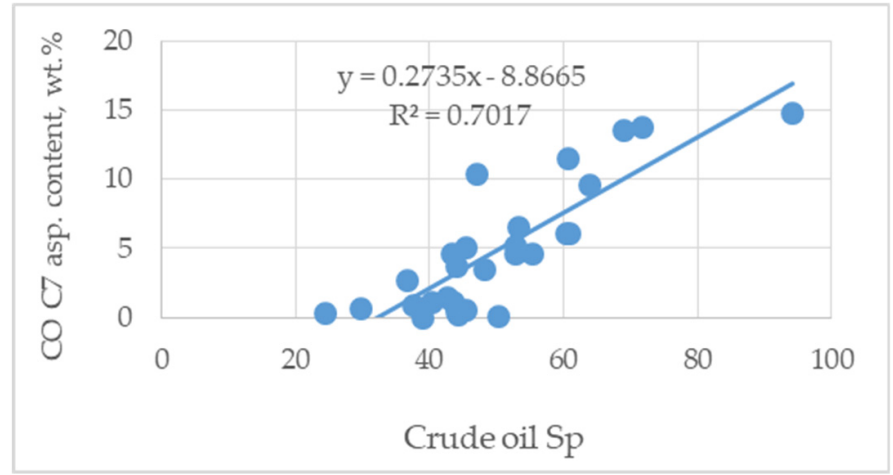

(b)

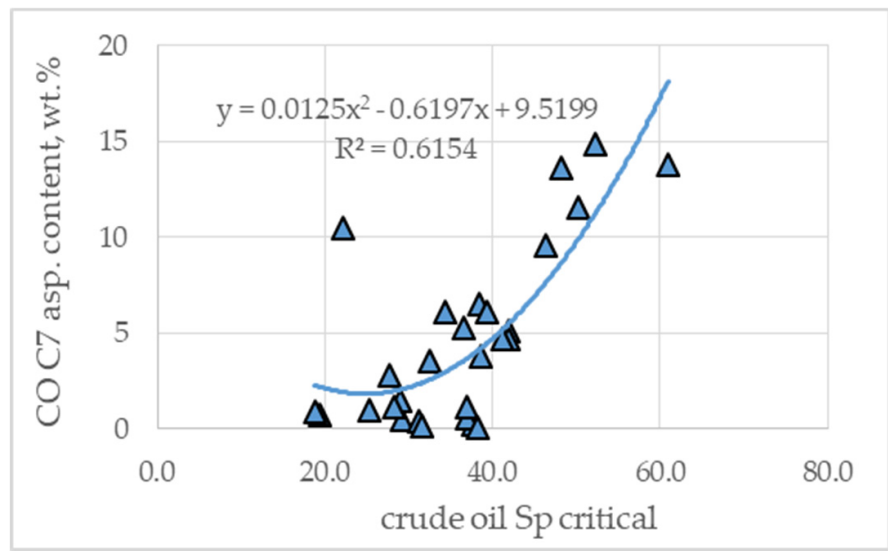

(d)

Figure 4. Dependence of solvent and critical solvent power on $C_{5}$ and $C_{7}$ asphaltene content of the studied crude oils: (a) relation between $S p$ and $C_{5}$ asphaltenes; (b) relation between $S p$ and $C_{7}$ asphaltenes; (c) relation between $S p$ critical and $\mathrm{C}_{5}$ asphaltenes; (d) relation between $\mathrm{Sp}$ critical and $\mathrm{C}_{7}$ asphaltenes. 
The following expression of the relation between solvent power and crude oil properties has been established (Equation (9)) by performing a multiple linear regression:

$$
\begin{gathered}
S p=34.76553+1.21187 \times C 5 A s p+0.10604 \times V i s+2.28072 \times S \\
R=0.93(\text { coefficient of multiple correlation), standard error }=5.7 \%
\end{gathered}
$$

In some cases, for light crude oils with $S_{B N} / I_{N}$ ratio below 1.4 and solvent power below 44 , which are considered to pertain to the group of incompatible and near-incompatible crude oils (for example El Boury, CPC, and Azeri Light), the estimated solvent power values by Equation (9) were out of the regression standard error (5.7\%), but in the range of uncertainty of the method for solvent power determination (5-15\%), as reported in [42] (Figure 5a).

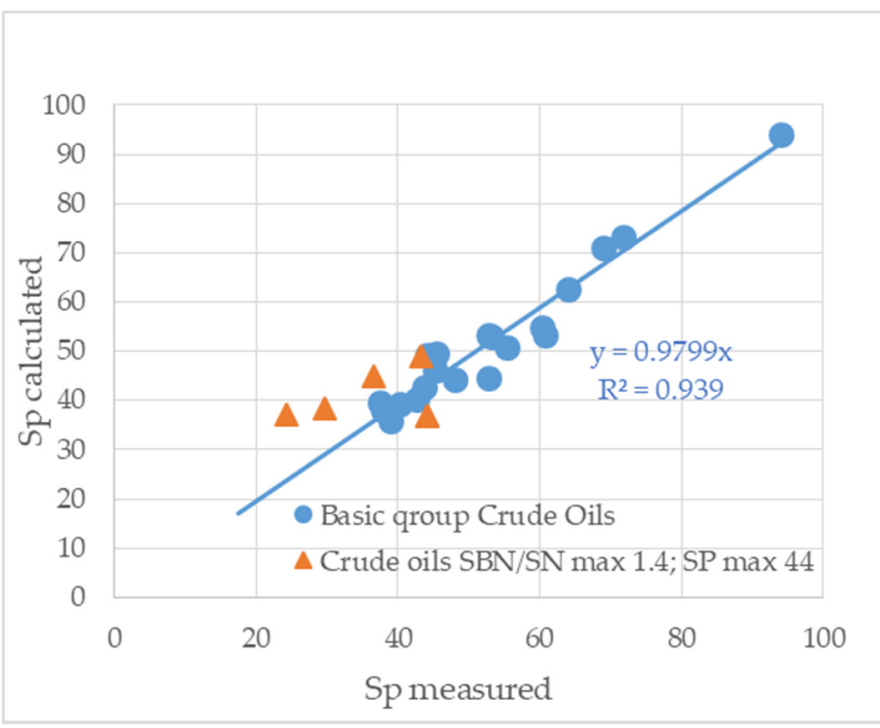

(a)

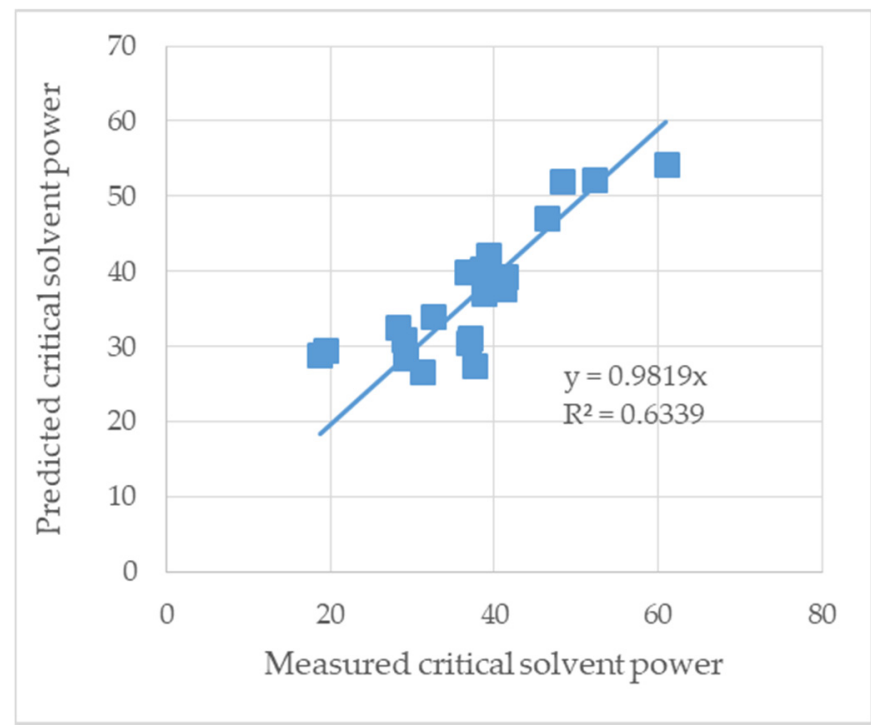

(b)

Figure 5. Agreement between the predicted and measured solvent power by Equation (9) (a), and by Equation (10) (b).

By performing a multiple linear regression, the following expression relating the critical solvent power to the $C_{5}$ asphaltene content, density of crude oil, and Conradson carbon content of the vacuum residue was developed.

Sp critical $=14.01745+1.127921 \times C 5 A s p+0.273233 \times C C R v r+11.65823 \times D$

$\mathrm{R}=0.85$ (coefficient of multiple correlation), standard error $=5.8 \%$

The standard error of Equation (10) is in the range of uncertainty of the method for critical solvent power determination (5-15\%) reported in [42] (Figure 5b). The laboratory experiments in LNB established that the typical error for solvent and critical solvent power determination did not exceed $10 \%$.

The regression Equation (9) suggests that the crude oils which have higher $\mathrm{C}_{5^{-}}$ asphaltene content, higher viscosity, and higher sulfur content are stronger solvents. On the other hand, regression Equation (10) implies that the higher $C_{5}$-asphaltene content crude oils are more difficult to dissolve and will require a stronger solvent to keep the asphaltenes in solution and prevent their precipitation. These findings are in line with those reported in our earlier study [17] showing that the higher asphaltene content crudes require blending with crude oils whose vacuum residue has a higher Conradson carbon content, and the petroleum has a higher density.

Similar to solvent power the $S_{B N}$ has a statistically meaningful relation with the crude oil density, sulfur, and $C_{5}$ asphaltene content (Figure 6). High sulfur crude oils with high content of $C_{5}$ and $C_{7}$ asphaltenes are characterized by a higher solubility blending 
number. It is well-known that solubility-blending number cannot be a self-sufficient parameter for crude oil compatibility evaluation [26]. The ratio between the solubility blending number and insolubility number was established as a reliable indicator that can determine the compatibility of the crude oils [27]. Figure 7 describes the $S_{B N} / I_{N}$ ratios of the investigated crude oils. As can be seen from the data in Figure 7 three zones can be defined: incompatible zone $S_{B N} / I_{N}<1$, near-incompatible zone $1<S_{B N} / I_{N}<1.4$, and compatible zone $S_{B N} / I_{N}>1$.4. It is evident from these data that both light and heavy crude oils pertain to the self-incompatible zone and near-incompatible zone, implying that all types of crude oil could belong to the group of the self-incompatible and near-incompatible oils. For this data set, no statistically meaningful relation was found between the insolubility number and any crude oil property.

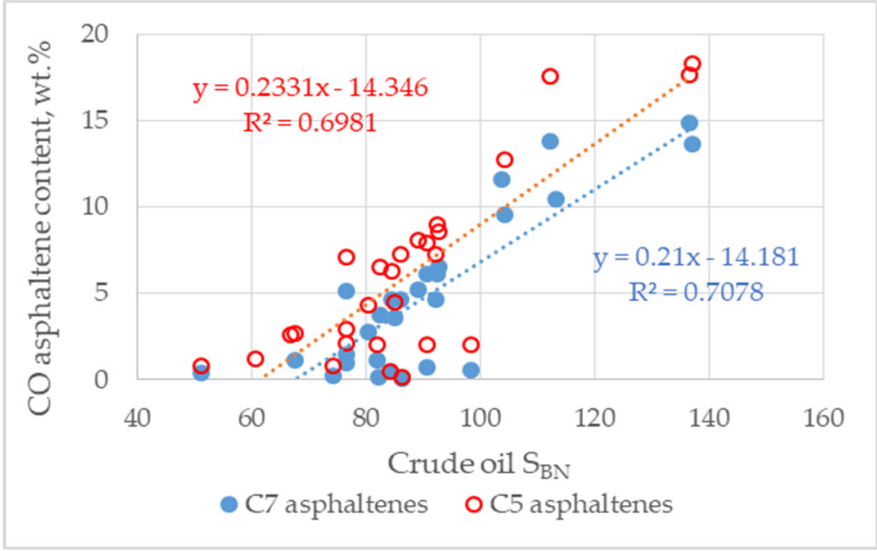

(a)

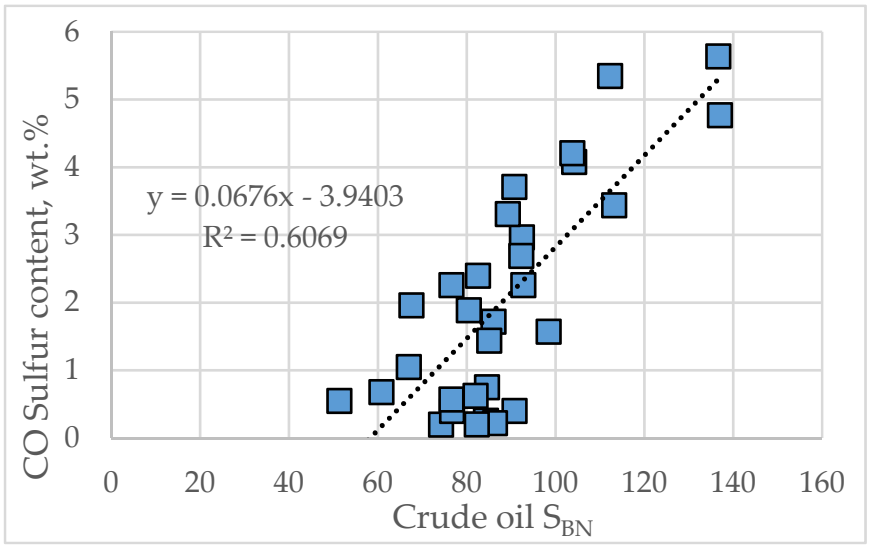

(b)

Figure 6. Dependence of solubility blending number on asphaltene (a) and sulfur (b) content of the studied crude oils.

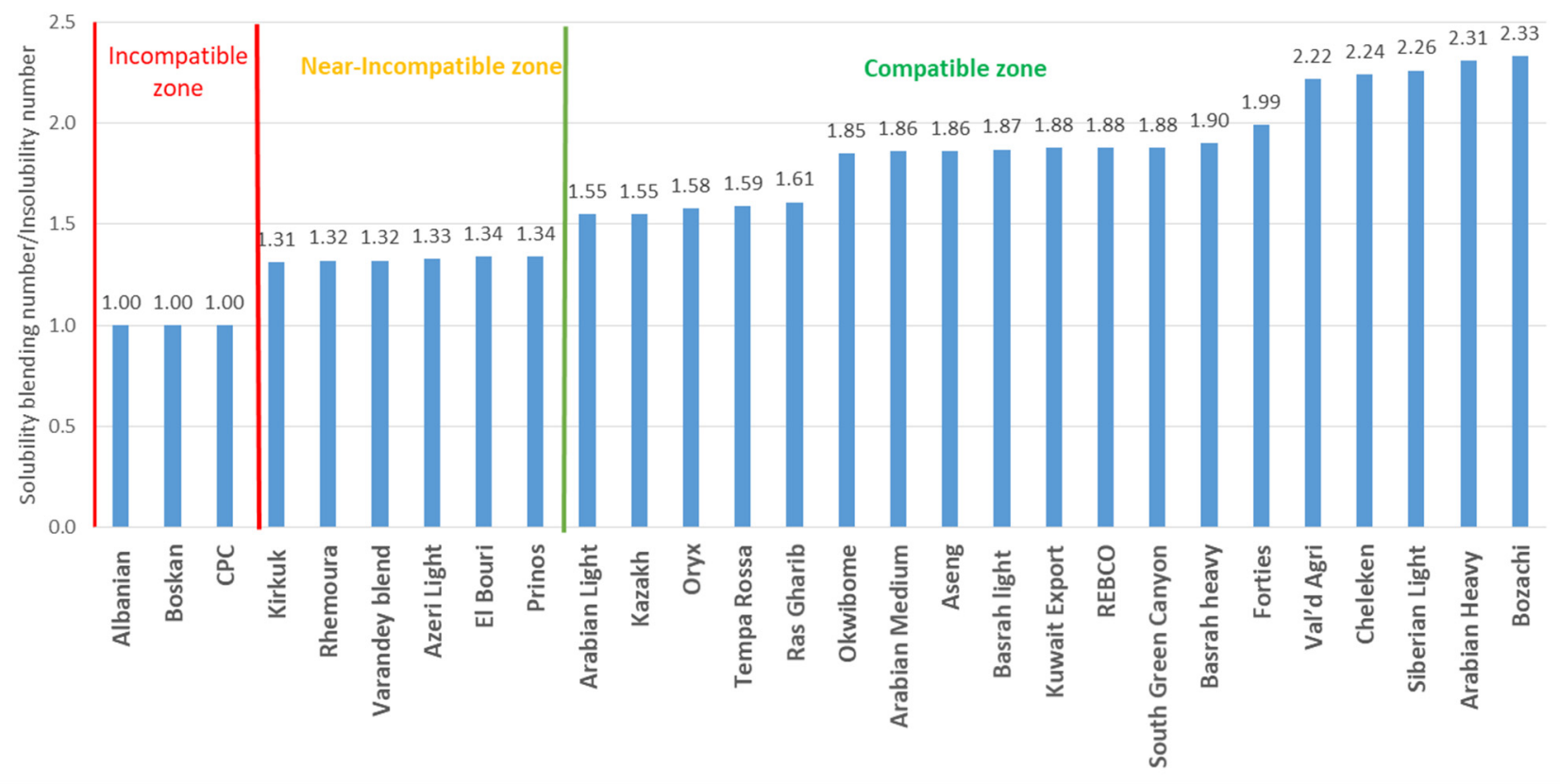

Figure 7. $S_{B N} / I_{N}$ ratios of the studied crude oils from different origins. 


\subsection{Relation between Compatibility Indices and Crude Desalting Efficiency}

Our previous study showed that the crude oil desalting efficiency is very important for the performance of the downstream units [49]. The desalting efficiency is defined as shown in Equation (11):

$$
D E=\frac{C O_{\text {salt }}-\text { desalted } C O_{\text {salt }}}{C O_{\text {salt }}} \times 100 \%
$$

Poor crude oil desalting entails upsets and increased corrosion in downstream units [49]. During processing different crude oil blends a variation of desalting efficiency between 70 and $96 \%$ was registered. All the studied compatibility indices in this work were examined for their relation to the desalting efficiency. Only the solvent power and the $S_{B N} / I_{N}$ ratio were found to have a statistically meaningful relation with the desalting efficiency as shown in Figure 8. As evident from the data in Figure 8 the ratio $S_{B N} / I_{N}$ is strongly related to the desalting efficiency than the solvent power. The crude oil blend with solvent power above 49 have a lower desalting efficiency. The solvent power of the crude oil is connected with its density and $K w$-factor (Table 5). When the density of crude oil blend increases (respectively solvent power), the difference between the densities of petroleum blend and water decreases and water salinity diminishes. A crude oil with 0.898 specific gravity with produced water salinity of $25 \%$ has a density difference about five times as high as that of a crude oil with 0.973 specific gravity with produced water salinity of $3 \%$ at $40{ }^{\circ} \mathrm{C}$ [66]. The extra-heavy crude oils and bitumen, heavier than water are diluted to a dilbit of 0.97 specific gravity; the dilbit becomes lighter than the water phase, and the water salinity is $0 \%$, typically [67]. Thus, for desalting and dehydration of heavier crude oil blends, the desalter will require more stringent operating conditions (temperate, type of chemical additives, wash water ratio, or settling time) [68] and design due to lower salinity in the diluted produced water in the desalter.

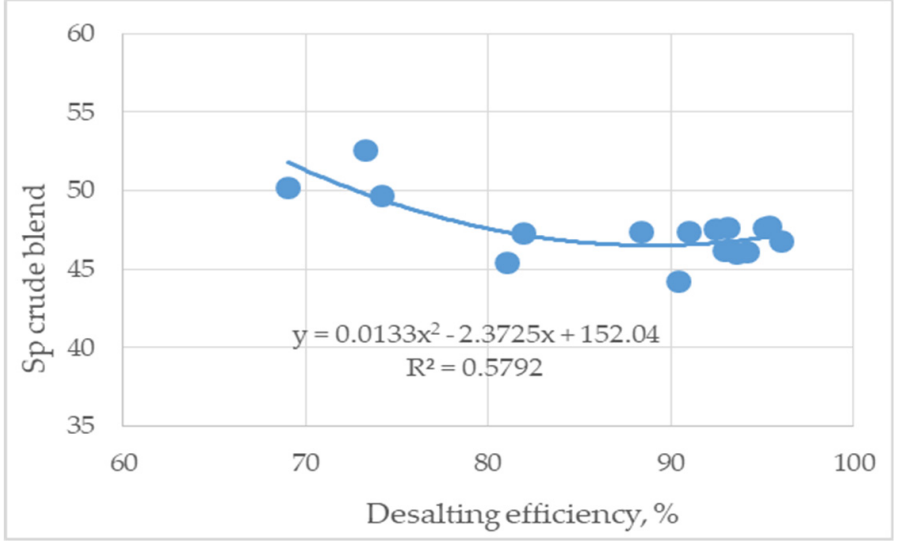

(a)

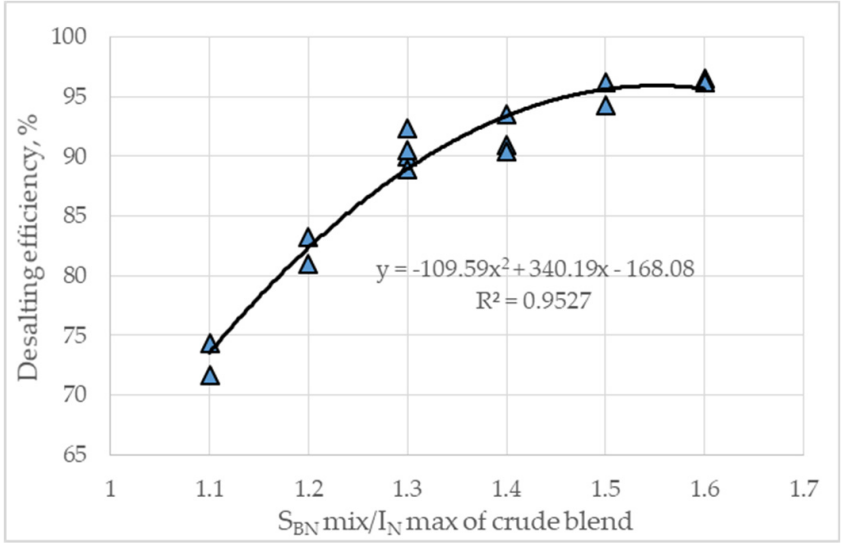

(b)

Figure 8. Dependence of desalting efficiency on solvent power (a) and ratio $S_{B N \operatorname{mix}} / I_{N \max }(\mathbf{b})$ of different crude oil blends processed in commercial desalter.

During processing of near-incompatible crude oil blends (ratio $S_{B N} / I_{N}<1.4$ ) a lower desalting efficiency was registered. Figure $8 \mathrm{~b}$ depicts the relation between ratio $S_{B N} / I_{N}$ and desalting efficiency, which is described by a second-order polynomial with $R^{2}=0.9527$. The insolubility number measures the degree of insolubility of the asphaltenes, and the solubility blending number measures the solvency of the oil for asphaltenes. The criterion of crude oil blend compatibility is $S_{B N \operatorname{mix}}>I_{\text {Nmax }}$, that is the solubility blending number of the mixture of oils must be higher than the insolubility number of any oil in the mixture [26]. The higher the $S_{B N m i x}$ the better its stability. On the other hand, the $S_{B N}$ is related to the asphaltene content in the crude oil (Figure 6). It is well-known that asphaltenes in the crude oil, as a surface-active substance, cause the formation of higher stability 
oil/water emulsions [14]. The asphaltenes hinder separation of oil and water phases during the desalting and dewatering because the asphaltene molecules easily gather at the oil/water interface and undergo self-association, hence forming a rigid film at the oil/water interface [14]. Moreover, solids such as high molecular paraffin and clay are adsorbed and the mechanical strength of the interfacial film becomes more rigid than ever [69]. When the crude blend is incompatible or near-incompatible and the asphaltenes are instable, the process of self-association at the oil/water interface may be accelerated resulting in the formation of a rigid film that deteriorates the desalting and dewatering efficiency.

A blend of 50.5 wt. $\%$ Urals, 20 wt. $\%$ CPC, 24.5 wt. $\%$ Arabian medium, and 5 wt. $\%$. Prinos $\left(S_{B N} / I_{N}=1.1, S p=42.9, S p\right.$ critical $\left.=32.1\right)$ was processed in the LNB refinery. The blend was determined as near-incompatible because the difference between $S p$ and $S p$ critical was in the limits of $10 \%$ error and the ratio $S_{B N} / I_{N}$ was below 1.4. A very low desalting efficiency $(70 \div 75 \%)$ was observed in the crude oil desalting unit.

The solvent compatibility indices and critical solvent power and solubility blending number and insolubility number determined on the base of the n-heptane dilution test and employment of Equations (2), (3), and (5)-(8) have been used to model the compatibility of a four-component crude oil blend. Tetra-Plot was used for representation of the compatibility of the four-component crude oil blend by using Equations (2) and (3) (solvent power and critical solvent power) and the procedure described in [70]. Figure 9 presents the obtained tetra-plot of crude oil blend Urals, CPC, Prinos, and Arabian medium crude oils by the use. Critical zone of mixing separates the zones of compatibility (in green) and incompatibility (in red) of the four-component blend. The critical curves of three-component blends are depicted. The critical point of two-component blend is also shown in Figure 9. It can be seen from these data that some of the critical points do not lie on the critical zone or curves. Two-component blend CPC/Urals is incompatible in the ratio $65 \% \mathrm{wt} . / 35 \% \mathrm{wt}$., but the addition of a third crude oil, as Arabian medium for example, can improve the stability of the petroleum blend and make it compatible.

$$
\diamond \text { incompatibility zone }
$$

CPC

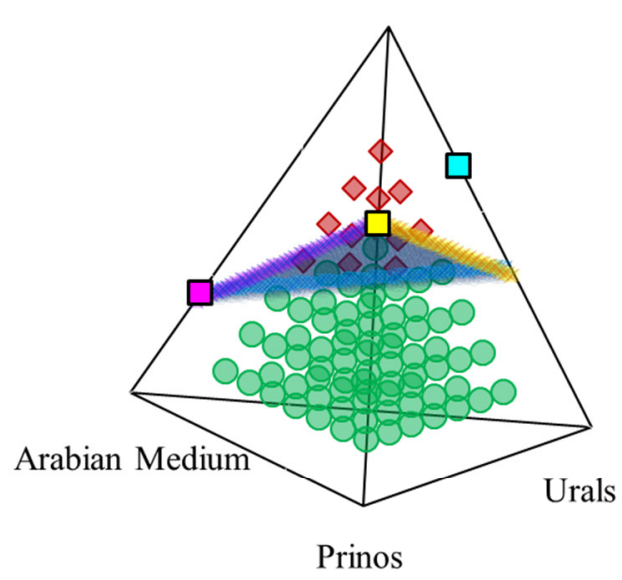

$$
\text { O compatibility zone }
$$

critical zone

$\times$ Arabian Medium - CPC - Urals critical curve

$\times$ Arabian Medium $-\mathrm{CPC}-$ Prinos critical curve

CPC - Urals - Prinos critical curve

口Arabian Medium 73\% - CPC 27\% critical point

口CPC $65 \%$ - Urals $35 \%$ critical point

口CPC $59 \%$ - Prinos $41 \%$ critical point

Figure 9. Tetra-plot of compatibility of crude oil blend Urals, Prinos, CPC, and Arabian medium using Sp and Sp critical indices.

Figure 10 indicates the tetra-plot of crude oil blend Urals, CPC, Prinos, and Arabian medium crude oils by using the data for solubility blending number and insolubility 
number. The data in Figure 10 do not significantly differ from the data in Figure 9. However, the use of solubility blending number and insolubility number predicts a lower space of incompatibility (Figure 10) than that employing solvent power and critical solvent power (Figure 9). This implies that the compatibility indices of solvent power and critical solvent power are more conservative and predict the incompatibility regions with lower degree of freedom concerning the variation in concentration of the four investigated crude oils for that case. Nevertheless, the compatibility indices of solubility blending number and insolubility number are better related to the desalting efficiency, supposing that they could be the more appropriate indices to assess crude blend compatibility reflecting the commercial field performance.

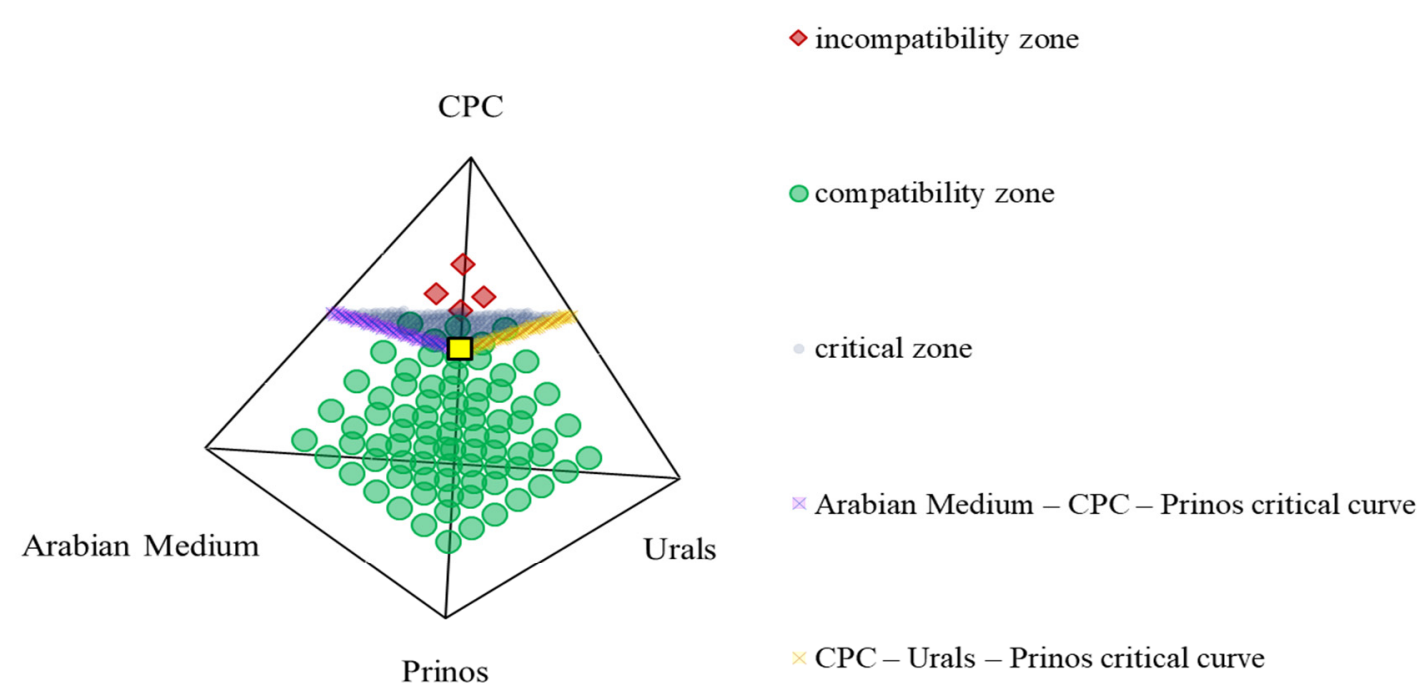

口CPC $59 \%$ - Prinos $41 \%$ critical point

Figure 10. Tetra-plot of compatibility of crude oil blend Urals, Prinos, CPC, and Arabian medium employing $S_{B N m i x}$ and $I_{\text {Nmax }}$ critical indices.

\section{Conclusions}

Nine crude oil compatibility indices were studied to evaluate the compatibility of crude blends from thirty individual crude oils. These crude oils belong to light, medium, heavy, and extra heavy, light sulfur, and high sulfur types. The compatibility indices, solvent power, solvent blending number determined on the base of the n-heptane dilution test were found to correlate with the petroleum density. The compatibility indices based on petroleum SARA analysis data, colloidal instability index, saturates/aromatics, and others also correlate with density. The solubility blending number and solvent power increase with augmentation of contents of asphaltenes and sulfur. The critical solvent power enhances with the magnification of crude oil density, content of crude oil asphaltenes, and vacuum residue Conradson carbon content. The desalting efficiency deteriorates when crude blends with lower ratio of solubility blending number to insolubility number and higher solvent power are processed. The ratio of solubility blending number to insolubility number was found to best describe the desalting efficiency, and therefore could be considered as the compatible index that best models the crude oil blend compatibility.

Author Contributions: Conceptualization, E.S.; Data curation, R.K.D. and S.N.; Formal analysis, D.Y.; Investigation, M.P.T. and L.T.-Y.; Methodology, S.S.; Software, V.A., S.R. and D.D.S.; Supervision, K.A.; Writing-original draft, I.K.S. and D.S.S. All authors have read and agreed to the published version of the manuscript. 
Funding: This research was funded by Asen Zlatarov University-Burgas, Project: Information and Communication Technologies for a Digital Single Market in Science, Education and Security DCM \# 577/17.08.2018 (2018-2021)

Institutional Review Board Statement: Not applicable.

Informed Consent Statement: Not applicable.

Data Availability Statement: Not applicable.

Acknowledgments: The authors are grateful for the support provided by the Bulgarian Ministry of Education and Science under the National Research Programme "Information and Communication Technologies for a Digital Single Market in Science, Education and Security" approved by DCM \# 577/17.08.2018.

Conflicts of Interest: The authors declare no conflict of interest.

\section{Nomenclature}

\begin{tabular}{|c|c|}
\hline Aro & Aromatics \\
\hline Asp & Asphaltenes \\
\hline CCR & Conradson carbon content, wt.\% \\
\hline CCRvor & $\begin{array}{l}\text { Conradson carbon content of the vacuum residue in crude oil (cut boiling above } \\
\left.540^{\circ} \mathrm{C}\right), \text { wt. } \%\end{array}$ \\
\hline CII & Colloidal instability index \\
\hline C5Asp & C5 asphaltene content in the crude oil, wt.\% \\
\hline C7Asp & C7 asphaltene content in the crude oil, wt.\% \\
\hline $\mathrm{CO}$ & Crude oil \\
\hline $\mathrm{CO}_{\text {salt }}$ & Crude oil salt content, mg/L \\
\hline $\mathrm{D}$ & Crude oil density at $15^{\circ} \mathrm{C}, \mathrm{kg} / \mathrm{L}$ \\
\hline$d$ & Crude oil density at $20^{\circ} \mathrm{C}, \mathrm{kg} / \mathrm{L}$ \\
\hline$D E$ & Crude oil desalting efficiency, $\%$ \\
\hline desalted $\mathrm{CO}_{\text {salt }}$ & Content of salts in desalted crude oil, $\mathrm{mg} / \mathrm{L}$ \\
\hline FBP & Final boiling point, ${ }^{\circ} \mathrm{C}$ \\
\hline HD & n-heptane Dilution \\
\hline HTSD & High temperature simulation distillation \\
\hline IBP & Initial Boiling point, ${ }^{\circ} \mathrm{C}$ \\
\hline $\mathrm{ICrA}$ & Intercriteria analysis \\
\hline $\mathrm{I}_{\mathrm{N}}$ & Insolubility number \\
\hline$K w$ & Watson characterization factor \\
\hline Kco & Characterization factor of the crude oil \\
\hline$K t$ & Characterization factor of the toluene \\
\hline Khp & Characterization factor of the $n$-heptane \\
\hline LNB & Lukoil Neftohim Burgas \\
\hline Res & Resins \\
\hline S & Crude oil Sulphur content, wt.\% \\
\hline SARA & Saturates, aromatics, resins, asphaltenes \\
\hline Sat & Saturates \\
\hline$S_{B N}$ & Solubility number of crude oil \\
\hline$S_{B N i}$ & Solubility number of $\mathrm{i}$ crude oil in the blend \\
\hline$S_{B N m i x}$ & Solubility number of the petroleum blend \\
\hline$S_{B N} / I_{N}$ & Solubility blending number/insolubility number ratio \\
\hline$S p$ & Solvent power of the crude oil \\
\hline Sp critical & Critical solvent power of the crude oil \\
\hline Sp blend & Solvent power of petroleum blend \\
\hline Spi & Solvent power of i crude oil; \\
\hline TBP & True boiling point \\
\hline$T 10$ & Boiling point of $10 \%$ of evaporate according to the HTSD or physical distillation, ${ }^{\circ} \mathrm{C}$ \\
\hline T30 & Boiling point of $30 \%$ of evaporate according to the HTSD or physical distillation, ${ }^{\circ} \mathrm{C}$ \\
\hline T50 & Boiling point of $50 \%$ of evaporate according to the HTSD or physical distillation, ${ }^{\circ} \mathrm{C}$ \\
\hline T70 & Boiling point of $70 \%$ of evaporate according to the HTSD or physical distillation, ${ }^{\circ} \mathrm{C}$ \\
\hline
\end{tabular}




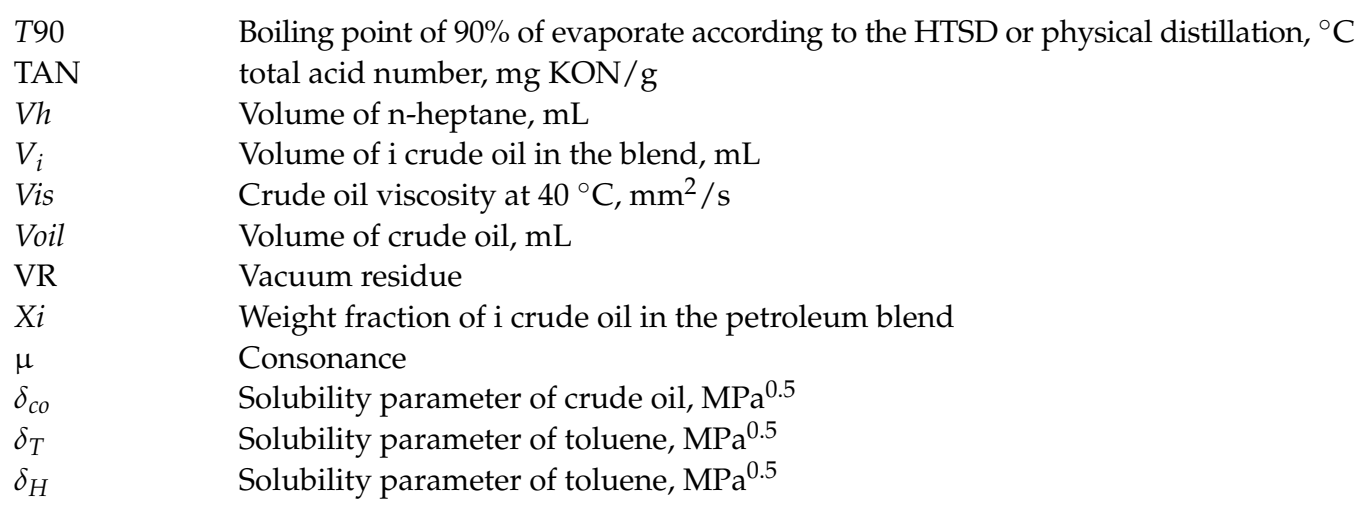

\section{References}

1. Ooms, A.C.; van den Berg, F.; Kapusta, S.D.; Nouwens, L.W. Processing Opportunity Crudes: A New Strategy for Crude Selection; ERTC: Madrid, Spain, 2001.

2. van den Berg, F.G.A.; Kapusta, S.D.; Ooms, A.C.; Smith, A.J. Fouling and compatibility of crudes as basis for a new crude selection strategy. Pet. Sci. Technol. 2003, 21, 557-568. [CrossRef]

3. Qing, W. Processing High TAN Crude: Part I. PTQ 2010, Q4. Available online: https://www.digitalrefining.com/article/100052 4/processing-high-tan-crude-part-i\#.YPUneugzaUk (accessed on 18 July 2021).

4. Santos, J.M.; Wisniewski, A., Jr.; Eberlin, M.N.; Schrader, W. Comparing Crude Oils with Different API Gravities on a Molecular Level Using Mass Spectrometric Analysis. Part 1: Whole Crude Oil. Energies 2018, 11, 2766. [CrossRef]

5. Ramirez-Corredores, M. The Science and Technology of Unconventional Oils; Elsevier Inc.: Amsterdam, The Netherlands; Academic Press: Cambridge, MA, USA, 2017.

6. Goldhammer, B.; Weber, C.; Christensen, P.; Yeung, S.; Garrett, T.; Yeung, T. Future of Opportunity Crudes Processing PTQ 2011, Q4. Available online: https://www.digitalrefining.com/article/1000384/future-of-opportunity-crudes-processing\#.YPZpBo0 zaUm (accessed on 18 July 2021).

7. Yeung, T.W. Evaluating Opportunity Crude Processing. PTQ 2006, Q4, 93. Available online: https:/ /www.digitalrefining.com/ article/1000644/evaluating-opportunity-crude-processing\#.YPZo7o0zaUk (accessed on 18 July 2021).

8. Kumar, R.; Voolapalli, R.K.; Upadhyayula, S. Prediction of crude oil blends compatibility and blend optimization for increasing heavy oil processing. Fuel Process. Technol. 2018, 177, 309-327. [CrossRef]

9. Saad, M.A.; Kamil, M.; Abdurahman, N.H.; Yunus, R.M.; Awad, O.I. An overview of recent advances in state-of-the-art techniques in the demulsification of crude oil emulsions. Processes 2019, 7, 470. [CrossRef]

10. Wiehe, I.A.; Kennedy, R.J. The Oil Compatibility Model and Crude Oil Incompatibility. Energy Fuels 2000, 14, 56-59. [CrossRef]

11. Wiehe, I.A. Self-incompatible crude oils and converted petroleum resids. J. Disper. Sci. Technol. 2004, 3, 333-339. [CrossRef]

12. Wiehe, I.A. Asphaltene Solubility and Fluid Compatibility. Energy Fuels 2012, 26, 4004-4016. [CrossRef]

13. Speight, J.G. Fouling in Refineries; Elsevier: Waltham, MA, USA, 2015.

14. Liu, G.; Xu, X.; Gao, J. Study on the Compatibility of Asphaltic Crude Oil with the Electric Desalting Demulsifiers. Energy Fuels 2003, 17, 543-548. [CrossRef]

15. Rogel, E.; Hench, K.; Miao, T.; Lee, E.; Dickakian, G. Evaluation of the Compatibility of Crude Oil Blends and Its Impact on Fouling Propensity. Energy Fuels 2018, 32, 9233-9242. [CrossRef]

16. Coletti, F.; Frederick, H.G. Crude Oil Fouling: Deposit Characterization, Measurements, and Modelling; Gulf Professional Publishing: Huston, TX, USA; Elsevier: Amsterdam, The Netherlands, 2015.

17. Stratiev, D.; Shishkova, I.; Nedelchev, A.; Kirilov, K.; Nikolaychuk, E.; Ivanov, A.; Sharafutdinov, I.; Veli, A.; Mitkova, M.; Tsaneva, T.; et al. Investigation of Relationships between Petroleum Properties and Their Impact on Crude Oil Compatibility. Energy Fuels 2015, 29, 7836-7854. [CrossRef]

18. Asomaning, S.; Watkinson, A.P. Petroleum stability and heteroatom species effects in fouling of heat exchangers by asphaltenes Heat Transf. Eng. 2000, 21, 10-16.

19. Evdokimov, I.N. The importance of asphaltene content in petroleum iii-New criteria for prediction of incompatibility in crude oil blends. Pet. Sci. Technol. 2010, 28, 1351-1357. [CrossRef]

20. Hong, E.; Watkinson, P. A study of asphaltene solubility and precipitation. Fuel 2004, 83, 1881-1887.

21. Saleh, Z.S.; Sheikholeslami, R.; Watkinson, A.P. Blending effects on fouling of four crude oils. In Proceedings of the 6th International Conference on Heat Exchanger Fouling and Cleaning-Challenges and Opportunities, Kloster Irsee, Germany, 5-10 June 2005; Müller-Steinhagen, M.H., Malayeri, R., Paul Watkinson, A., Eds.; Engineering Conferences International: New York, NY, USA, 2005.

22. Hong, E.; Watkinson, P. Precipitation and fouling in heavy oil-diluent blends. Heat Transf. Eng. 2009, 30, 786-793.

23. Asomaning, S. Test Methods for Determining Asphaltene Stability in Crude Oils. Pet. Sci. Technol. 2003, 21, 581-590. [CrossRef]

24. ASTM D4740-04(2014). Standard Test Method for Cleanliness and Compatibility of Residual Fuels by Spot Test; ASTM International: West Conshohocken, PA, USA, 2014. 
25. Schermer, W.E.M.; Melein, P.M.J.; van den Berg, F.G.A. Simple Techniques for Evaluation of Crude Oil Compatibility. Pet. Sci. Technol. 2004, 22, 1045-1054. [CrossRef]

26. Wiehe, I.A.; Kennedy, R.J. Application of the Oil Compatibility Model to Refinery Streams. Energy Fuels 2000, 14, 60-63. [CrossRef]

27. Wiehe, I.A.; Kennedy, R.J.; Dickakian, G. Fouling of Nearly Incompatible Oils. Energy Fuels 2001, 15, 1057-1058. [CrossRef]

28. Mahmoud, M.B.; Aboujadeed, A.A. Compatibility Assessment of Crude Oil Blends Using Different Methods. Chem. Eng. Trans. 2017, 57, 1705-1710.

29. Gabrienko, A.A.; Subramani, V.; Martyanov, O.N.; Kazarian, S.G. Correlation between Asphaltene Stability in n-Heptane and Crude Oil Composition Revealed with In Situ Chemical Imaging. Adsorp. Sci. Technol. 2014, 32, 243-255. [CrossRef]

30. Rogel, E.; Hench, K.; Hajdu, P.; Ingham, H. Chapter 7: The role of compatibility in determining the blending and processing of crude oils. In Chemistry Solutions to Challenges in the Petroleum Industry; Rahimi, P., Ovalles, C., Zhang, Y., Adams, J.J., Eds.; ACS Symposium Series; American Chemical Society: Washington, DC, USA, 2019.

31. Rogel, E.; Ovalles, C.; Moir, M. Asphaltene Stability in Crude Oils and Petroleum Materials by Solubility Profile Analysis. Energy Fuels 2010, 24, 4369-4374. [CrossRef]

32. da Silva Ramos, A.C.; Rolemberg, M.P.; de Moura, L.G.M.; Zilio, E.L.; dos Santos, M.F.P.; González, G. Determination of Solubility Parameters of Oils and Prediction of Oil Compatibility. J. Petrol. Sci. Eng. 2013, 102, 36-40. [CrossRef]

33. Gharbi, K.; Benyounes, K.; Khodja, M. Removal and Prevention of Asphaltene Deposition during Oil Production: A Literature Review. J. Petrol. Sci. Eng. 2017, 158, 351-360. [CrossRef]

34. Fakher, S.; Ahdaya, M.; Elturki, M.; Imqam, A. Critical Review of Asphaltene Properties and Factors Impacting its Stability in Crude Oil. J. Pet. Explor. Prod. Technol. 2020, 10, 1183-1200. [CrossRef]

35. Hemmati-Sarapardeh, A.; Ahmadi, M.; Ameli, F.; Dabirb, B.; Mohammad, A.H.; Husein, M.M. Modeling asphaltene precipitation during natural depletion of reservoirs and evaluating screening criteria for stability of crude oils. J. Pet. Sci. Eng. 2019, $181,106127$. [CrossRef]

36. Guzmán, R.; Ancheyta, J.; Trejo, F.; Rodríguez, S. Methods for determining asphaltene stability in crude oils. Fuel 2017, 188, 530-543. [CrossRef]

37. Tharanivasan, A.K.; Svrcek, W.Y.; Yarranton, H.W. Measurement and modeling of asphaltene precipitation from crude oil blends. Energy Fuels 2009, 23, 3971-3980. [CrossRef]

38. Rodríguez, S.; Ancheyta, J.; Guzmán, R.; Trejo, F. Experimental setups for studying the compatibility of crude oil blends under dynamic conditions. Energy Fuels 2016, 30, 8216-8225. [CrossRef]

39. Moura, L.G.M.; Santos, M.F.P.; Zilio, E.L.; Rolemberg, M.P.; Ramos, A.C.S. Evaluation of indices and of models applied to the prediction of the stability of crude oils. J. Pet. Sci. Eng. 2010, 74, 77-87. [CrossRef]

40. de la Cruz, J.L.M.; Cedillo-Ramírez, J.C.; Aguirre-Gutiérrez, A.J.; García-Sánches, F.; Aquino-Olivos, M.A. Incompatibility determination of crude oil blends from experimental viscosity and density data. Energy Fuels 2015, 29, 480-487. [CrossRef]

41. Stankiewicz, A.B.; Flannery, M.D.; Fuex, N.Q.; Broze, G.; Couch, J.L.; Dubey, S.T.; Iyer, S.D. Prediction of asphaltene deposition risk in E\&P operations. In Proceedings of the Third International Symposium on Mechanisms and Mitigation of Fouling in Petroleum and Natural Gas Production, AIChE, New Orleans, LA, USA, 10-14 March 2002.

42. Nemana, S.; Kimbrell, M.R.; Zaluzec, E. Predictive Crude Oil Compatibility Model. U.S. Patent 7,618,822 B2, 28 May 2009.

43. Wiehe, I.A.; Kennedy, R.J. Process for Blending Potentially Incompatible Petroleum Oils. U.S. Patent 5,871,634, 16 February 1999.

44. Kumar, R.; Voolapalli, R.K.; Rakshit, P.R.; Bhargava, S.; Upadhyayula, S. Predicting of crude oil blend compatibility and blend optimization for increasing heavy oil processing. U.S. Patent 2019/0234928, 1 August 2019.

45. Hascakir, B.; Punase, A. Method and System for Stability Determination of Asphaltenes Utilizing Dielectric Constant Measurements. U.S. Patent 10,620,145, 14 April 2018.

46. Punase, A.; Prakoso, A.A.; Hascakir, B. The polarity of crude oil fractions affects the asphaltenes stability. In Proceedings of the SPE Western Regional Meeting, Anchorage, AK, USA, 23-26 May 2016.

47. Punase, A.; Hascakir, B. Stability determination of asphaltenes through dielectric constant measurements of polar oil fractions. Energy Fuels 2016, 31, 65-72. [CrossRef]

48. Prakoso, A.A.; Punase, A.D.; Hascakir, B. A mechanistic understanding of asphaltenes precipitation from varying-saturateconcentration perspectives. SPE Prod. Oper. 2016, 32, 86-98.

49. Stratiev, D.; Yankov, V.; Petrov, I.; Shishkova, I.; Pavlova, A.; Ivanova, P.; Surleva, A.; Hristov, K.; Todorova, E.; Obryvalina, A.; et al. Study on the origin of sediment formation in a high pressure near zero sulfur diesel hydrotreater. Fuel Process. Technol. 2014, 126, 332-342. [CrossRef]

50. Stratiev, D.; Shishkova, I.; Nikolova, R.; Tsaneva, T.; Mitkova, M.; Yordanov, D. Investigation on precision of determination of sara analysis of vacuum residual oils from different origin. Pet. Coal 2016, 58, 109-119.

51. Stratiev, D.; Shishkova, I.; Nikolaychuk, E.; Atanasova, V.; Atanassov, K. Investigation of relations of properties of straight run and h-oil unconverted vacuum residual oils. Pet Coal 2019, 61, 763-776.

52. Stratiev, D.; Shishkova, I.; Nikolaychuk, E.; Ijlstra, W.; Holmes, B.; Caillot, M. Feed properties effect on the performance of vacuum residue ebullated bed H-Oil hydrocracking. Oil Gas Eur. Mag. 2019, 4, 194-199.

53. Stratiev, D.; Shishkova, I.; Ivanova, N.; Veli, A.; Nikolova, R.; Mitkova, M.; Stanulov, K.; Argirov, G.; Yordanov, D.; Nikolaychuk, E. Colloidal stability and hot filtration test of residual fuel oils based on visbreaking and ebullated bed residue H-Oil hydrocracking. Int. J. Oil. Gas. Coal Technol. 2019, 20, 169-188. [CrossRef] 
54. Gharagheizi, F; Fazeli, A. Prediction of the Watson characterization factor of hydrocarbon components from molecular properties. QSAR Comb. Sci. 2008, 227, 758-767. [CrossRef]

55. Patil, P.D.; Kozminski, M.; Peterson, J.; Kumar, S. Fouling diagnosis of pennsylvania grade crude blended with opportunity crude oils in a refinery crude unit's hot heat exchanger train. Ind. Eng. Chem. Res. 2019, 58, 17918-17927. [CrossRef]

56. Yang, Z.; Ma, C.M.; Lin, X.S.; Yang, J.T.; Guo, T.M. Experimental and modeling studies on the asphaltene precipitation in degassed and gas-injected reservoir oils. Fluid Phase Equilibria 1999, 157, 143-153. [CrossRef]

57. Correra, S.; Merlini, M.; Di Lullo, A.; Merino-Garcia, D. Estimation of the solvent power of crude oil from density and viscosity measurements. Ind. Eng. Chem. Res. 2005, 44, 9307-9315. [CrossRef]

58. Al-Hosani, A.; Ravichandran, S.; Daraboina, N. Review of asphaltene deposition modeling in oil and gas production. Energy Fuels 2021, 35, 965-986. [CrossRef]

59. Rogel, E.; Ovalles, C.; Vien, J.; Moir, M. Asphaltene characterization of paraffinic crude oils. Fuel 2016, 178, 71-76. [CrossRef]

60. Joonaki, E.; Hassanpouryouzband, A.; Burgass, R.; Hase, A.; Tohidi, B. Effects of Waxes and the Related Chemicals on Asphaltene Aggregation and Deposition Phenomena: Experimental and Modeling Studies. ACS Omega 2020, 5, 7124-7134. [CrossRef] [PubMed]

61. D'Avila, F.G.; Silva, C.M.F.; Steckel, L.; Ramos, A.C.S.; Lucas, E.F. Influence of Asphaltene Aggregation State on the Wax Crystallization Process and the Efficiency of EVA as a Wax Crystal Modifier: A Study Using Model Systems. Energy Fuels 2020, 34, 4095-4105. [CrossRef]

62. del Carmen García, M.; Carbognani, L. Asphaltene-Paraffin Structural Interactions. Effect on Crude Oil Stability. Energy Fuels 2001, 15, 1021-1027. [CrossRef]

63. Stratiev, D.; Nenov, S.; Shishkova, I.; Georgiev, B.; Argirov, G.; Dinkov, R.; Yordanov, D.; Atanassova, V.; Vassilev, P.; Atanassov, K. Commercial Investigation of the Ebullated-Bed Vacuum Residue Hydrocracking in the Conversion Range of 55-93\%. ACS Omega 2020, 51, 33290. [CrossRef]

64. Vargas, F.M.; Tavakkoli, M. Asphaltene Deposition: Fundamentals, Prediction, Prevention, and Remediation; CRC Press: Boca Raton, FL, USA, 2018.

65. Xiong, R.; Guo, J.; Kiyingi, W.; Feng, H.; Sun, T.; Yang, X.; Li, Q. Method for Judging the Stability of Asphaltenes in Crude Oil. ACS Omega 2020, 5, 21420-21427. [CrossRef]

66. Sellman, E.; Mandewalkar, P. Highly Efficient Dehydration and Desalting of Crude Oil from Mature Fields in the Middle East. In Proceedings of the SPE Annual Technical Conference and Exhibition, Dubai, United Arab Emirates, 26 September 2016.

67. Moretto, J. Bitumen Processing-A Guide to Crude Oil Unit Revamps. In Proceedings of the 109th NPRA Annual Meeting, San Antonio, TX, USA, 21 March 2011.

68. Vafajoo, L.; Ganjian, K.; Fattahi, M. Influence of key parameters on crude oil desalting: An experimental and theoretical study. J. Pet. Sci. Eng. 2012, 90-91, 107-111. [CrossRef]

69. Kim, Y.H.; Wasan, D.T. Effect of demulsifier partitioning on the destabilization of water-in-oil emulsions. Ind. Eng. Chem. Res. 1996, 35, 1141-1149. [CrossRef]

70. Cucciniello, C. Tetra-Plot: A Microsoft Excel spreadsheet to perform tetrahedral diagrams. Period. Mineral. 2016, 85, 115-119. 